\title{
Articulating the Geo-Cultural Logic of Nationalist Insurgency
}

\author{
Lars-Erik Cederman \\ Swiss Federal Institute of Technology (ETH) \\ Center for Comparative and International Studies (CIS) \\ Seilergraben 49 \\ 8092 Zurich Switzerland \\ $+41-1-6326759$ \\ lcedermandethz.ch \\ Version 1.01 \\ Comments welcome! \\ January 13, 2004
}

\begin{abstract}
:
Logistical factors have assumed an increasingly important role in studies of civil wars. In particular, political economists have recently proposed models of insurgency that depend on states' capacity to project power in rugged terrain rather than on ethnic allegiances. Yet, a large gap remains between the observed macro-level patterns and the postulated rationalistic micro-level explanations. Aiming to reproduce similar, logistical macro-level patterns, this paper offers an alternative account that interprets insurgency as processes of nationalist mobilization leading to violence when the power balance favors the peripheral communities over the centers. To articulate such identity-based mechanisms, I rely on a computational model, whose cross-national output is analyzed with multivariate regressions. The computational findings suggest that the search for explanations of civil wars needs to go beyond purely rationalist conjectures.
\end{abstract}

*) Paper prepared for presentation at the workshop on "Origins and Patterns of Political Violence I: Violence in Civil Wars," to be held at the Santa Fe Institute, January 15-19, 2004. I would like to thank Luc Girardin for excellent computational advice and support. 


\section{Introduction}

As interstate wars become less frequent, academic attention has shifted increasingly to internal conflict. In recent years, an exciting literature on the determinants of civil wars has emerged. Political economists, relying on cross-national statistics and rational-choice modeling, have played a prominent role in this debate. Explaining outbreaks of civil wars in materialist and logistical, rather than in cultural, terms, an important study by Fearon and Laitin (2003) interprets such conflicts as instances of armed insurgency. Wherever the central state is weak and fails to reach the periphery due to difficult geography, rebellions become more likely. However, the authors find that the ethnic composition of the state in question has no impact on the likelihood of conflict.

There can me no doubt that work of this kind has advanced greatly the research frontier. Instead of sweeping generalizations based on diffuse and scattered case-study evidence, political economists have brought the phenomenon in sharper focus thus allowing for a more precise evaluation of their and others' hypotheses. Yet, it is somewhat premature to draw definitive theoretical conclusions from these studies, because there is a considerable gap between their macro-level findings and the rationalistic micro-level mechanisms that they posit as explanations. As the latter remain unsupported by direct evidence, one cannot exclude alternative causal mechanisms that deviate quite radically from these scholars' materialist conjectures.

Several studies have appeared that take issue with the statistical interpretations proposed by Fearon and Laitin, to which I will return shortly. In this paper, however, the goal is not to question their key findings so much as to articulate alternative causal mechanisms that bring both politics and culture back to the fore. Such a task calls for deeper and more systemic explanations than those associated with standard methods and assumptions of political economy. Therefore, I rely on computational modeling, which is better suited to trace historical path-dependency and to capture intangible entities such as national identities.

Contrary to the rationalistic reconstructions of Fearon and Laitin, I show that it is possible to create plausible scenarios in which state strength and terrain matter, although the effect is primarily mediated through geo-cultural mechanisms. The main goal is to create an artificial world within which peripheral insurgents manage to form coalitions, the effectiveness of which depends on inclusiveness of their shared national identity. Before creating such interactions in greater detail, however, it is necessary to "grow" a comprehensive, geo-cultural system, which includes geography, political organizations, cultural raw material, and national identities.

Based on a simple geo-cultural logic, the model generates results that are very similar to those found in Fearon and Laitin's theory of insurgency, both in terms of state strength and rugged terrain. Unlike the expectations of these authors, however, the model's insurrectional mechanisms hinge directly on national identities, and thus indirectly on the ethnic preconditions of the state in question. To confirm the power of nationalist identityformation while controlling for materialist factors, I run multivariate regressions on the model's output. This analysis suggests that it is often hard, if not even impossible, to separate political-economy interpretations from constructivist theorizing merely based on quantitative macro-level analysis.

In the following, I first review the relevant literature before introducing the four main phases of the computational model. After having specified the model, the attention turns to the computational main findings, followed by a section subjecting them to sensitivity analysis. A concluding section elaborates the theoretical and empirical consequences of the present study. 


\section{The contemporary literature on civil wars}

There can be no doubt about the policy relevance of civil wars. Whereas interstate warfare has declined in recent years, intrastate conflict shows few signs of abating (Sollenberg and Wallensteen 2001; Gleditsch et al 2002). It is therefore not surprising that scholars, both in comparative politics and international relations, have joined forces in a series of systematic attempts to account for why civil wars break out and why they persist (Lake 2003). Many of the recent research activities in this area draw on the availability of large-N data from sources such as Gurr's Minorities at Risk project (Gurr 1993) and improved, more fine-tuned measurements of internal conflict (Gleditsch et al. 2002).

Marrying such quantitative tools with rational-choice modeling, political economists have been leading in advancing candidate explanations along rationalistic lines. These studies tend to ascribe more explanatory power to materialist factors relating to the opportunity structure of rebellious activities than to ethnic divisions of the state in question (for a review, see Sambanis 2003). While several studies have appeared that propose variations on this theme (see e.g. Collier and Hoeffler 2002; Skaperdas 2003), a recent article by Fearon and Laitin (2003) stands out as particularly well-researched and provocative. ${ }^{\mathrm{r}}$

Contending that state strength and the logistical conditions of the rebels to a large extent determine the chances of civil war, Fearon and Laitin (2003, p. 75) define insurgency as "a technology of military conflict characterized by small, lightly armed bands practicing guerilla warfare from rural base areas." Based on this definition, they "hypothesize that financially, organizationally, and politically weak central governments render insurgency more feasible and attractive due to weak local policing or inept and corrupt insurgency practices" (pp. 75-76). Furthermore, such a logic implies that insurgency should become easier to carry out in rough and mountainous terrain (see also Collier and Hoeffler 2002).

Less than a year after its publication, Fearon and Laitin's article has already drawn considerable fire. Representing the state of the art in terms of methodology, it serves as a useful reference point for critiques and re-analyses. Relying on Bayesian analysis to correct for measurement error, Quinn, Hechter, and Wibbels (2003) confirm Fearon and Laitin's contention that weak states are more violence prone, but cast doubt on ethnic diversity's alleged irrelevance. In contrast, Sambanis (2003) probes the causal reasoning of the authors based on an impressive series of case studies rather than on statistics, but comes to similar critical conclusions. Also preoccupied with measurement error caused by Fearon and Laitin's reliance on imperfect proxies, he shows that their postulated mechanisms deviate from the empirical record in many of the cases. Most importantly, the political economists' tendency to aggregate all instances of civil war into one category obscures the diversity of causal logics. There is no a-priori reason to believe that the same mechanisms explain both coups within stable borders and secessionist attempts. Indeed, disaggregation demonstrates that in wars over self-determination, ethnic cohesion among the peripheral rebels supports collective mobilization against the central government (Sambanis and Zinn 2003). It is equally plausible that several mechanisms, rational or not, co-exist in the same civil war (Kalyvas 2003).

In his dissertation research, Kocher (2003) also uses Fearon and Laitin's study as a point of departure. His aim is to build a more refined theory of insurrectional civil war that relies more explicitly on ecological analysis. In this theory, state penetration of geographically remote areas is more important than sheer strength. Controlling for urbanization, Kocher finds that the standard indicators of state strength become spurious

\footnotetext{
${ }^{1}$ See also the special issues of Journal of Conflict Resolution (2001) and the Journal of Peace Research (2002).
} 
thus undermining the key interpretation advanced by Fearon and Laitin. Based on recoded GIS-generated data, his research also indicates that internal conflict is closely linked to difficult terrain, something that is more in line with the conventional literature. In contrast to Quinn et al. and Sambanis, however, his analysis also agrees with Fearon and Laitin in suggesting that ethnic fragmentation has no impact on civil war incidence. However, focusing on the configuration of settlement patterns, Toft (2003) anticipates Kocher's results about urbanization in a theory that includes ethnic groups as salient actors.

What are we to make of this intriguing, if somewhat contradictory, picture? The single most important puzzle relates to the articulation of mechanisms. True to their rationalistic inclinations, the political economists have relied on rational-choice models as a way to bridge the micro-macro gap. Although there is obviously no complete consensus among these scholars as regards the postulated mechanisms, their theoretical reconstructions are internally consistent and often elegant. Nevertheless, due to the looseness of the macrolevel indicators and proxies used, and in the absence of extensive micro-level validation, it would be unwise to place too much confidence in such conjectures. In his stimulating review of the literature, Sambanis $(2003$, p. 1) sums up the situation cogently:

The gap between micro-level behavior and macro-level explanation is large. It is magnified when micro-macro relationships are studied solely through crossnational statistical analyses. What is often lost in such studies in information about causal pathways that link outcomes with causes.

After all, the macro-level patterns could have been produced by radically different causal mechanisms, possibly even including the cultural ones that Fearon and Laitin choose to dismiss. Therefore, it would seem reasonable to heed Sambanis' (2003, p. 12) call urging researchers to "consider a wider array of micro-level theories, including how emotions, ideology, revenge, or private material interest interact to produce collective action that culminates in a civil war." Similarly, Quinn, Hechter, and Wibbels (2003, p. 13) insist that their "demonstration that cultural variables are important determinants of civil strife does not elucidate the mechanisms that are responsible for their efficacy. Causal mechanisms of outcomes like civil war require evidence about units at a lower level of aggregation than the state."

Most pragmatic social scientists would have few disagreements with the thrust of these critiques. Yet, it remains unclear where to look for alternative theoretical theories to fill the cultural void left open by the political economists. For sure, neither of the critiques considered here offers very clear guidance as to where to look for coherent theories in which to embed non-materialist mechanisms. Moreover, constructivist theory has not managed to live up to the same high standards of internal consistency and systematic validation as have their rationalistic counterparts (Fearon and Laitin 2000). Being preoccupied with mental events rather than with macro-level processes, constructivists have had just as great difficulties at advancing complex relational theories as do their rationalist colleagues (McAdam, Tarrow, and Tilly 2001; Tilly 2003; Cederman 2002b; Cederman and Daase 2003).

My contention is that historical sociology goes a long way toward providing the missing conceptual pieces in the explanatory jigsaw. There are striking parallels between the cases at hand and Rokkan's (1999) classical theory of European state-formation and nation-building. At the heart of his model is a similar center-periphery relationship as that proposed by Fearon and Laitin (2003), and Kocher (2003). In fact, Rokkan insists that "any analysis of variations among political systems must start from notions of territory" and proceeds by specifying his three main building blocks as centers, peripheries, and 
transactions, the latter linking the centers to the peripheries. Because transactions have to respect logistical constraints, it is necessary to study the physical, technological, military, economic, and cultural conditions of communication. Even from this brief enumeration it becomes evident that Rokkan's framework steers clear of the political economists' materialist reductionism. For peripherality in Rokkan's conception means much more than a physical struggle for power. In his more nuanced picture, peripheries are characterized by distance, difference, and dependence:

A periphery is located at some distance from the dominant centre or centres, and its transactions with the latter are fraught with costs. A periphery is also different from the central areas on one or more scores: while the degree of distinctiveness will vary, being to some extent a function of distances and dependence, there will invariably be some minimum level and sense of separate identity. Finally, a periphery is dependent upon one or more centres ... in political decision-making, in cultural standardization, and in economic life (p. 115).

By stressing identity-formation, Rokkan's account belongs to a long and prominent series of studies that draws the link between cultural standardization and political mobilization. In a classic study of rural France in the 19th century, E. Weber (1976) adopts a multidimensional perspective on a political center's cultural penetration of the periphery with the aid of road building, educational reforms, and other institutional mechanisms. Other classical accounts along similar lines include Hintze (1975), Deutsch (1953), and Gellner (1983). In addition, there are excellent, empirical studies that stress identity-formation in a regional context. Focusing on Southern Asia, Weiner's (1978) identifies a pattern that he refers to as the "sons of the soil," which spawns conflicts between settlers from the capital clashing with ethnically distinct peripheral populations. ${ }^{2}$ Likewise, there is a cultural dimension in Herbst's (2000) stimulating study of failed nation-building in the geographical periphery of African states.

To say that nation-building is important does not mean that one has found a full-fledged theory. The strength of Rokkan's system building lies at the macro level rather than at the level of micro-level mechanisms. Moreover, Rokkan's research did not focus on violent conflict as much as on cleavage structures and party politics. In recent years, however, considerable conceptual progress has been made in the study of "contentious politics," both as regards an ontological shift toward relational theorizing and an increased epistemological stress on causal mechanisms as the key to explanation (McAdam, Tarrow, and Tilly 2001; Tilly 2003). It is in the spirit of that promising research program that I embark on the task of articulating the geo-political logic of nationalist insurgency. For a lot of work remains until Rokkan's sweeping generalizations and macro processes can be translated into anything that resembles operational empirical research in general, and the empirical literature on civil wars in particular. The remainder of this paper sets out to bridge this gap with computer-based tools.

\section{A computational model of nationalist insurgency}

Agent-based modeling has emerged as an increasingly popular complement to conventional, rational-choice methods. By representing distinct actors in their social (and often spatial) context, this computational technique enables the analyst to represent complex, macro-level processes without losing their micro-level mechanisms out of sight. Moreover, intangible concepts, such as culture and social identities, which do not easily

\footnotetext{
${ }^{2}$ Interestingly, Fearon (2002) offers a partly inductive analysis of the duration of civil wars that confirms the power of Weiner's explanation.
} 
fit into a rationalistic framework, can be readily formalized and integrated into agentbased models (Cederman 1997, Chap. 3). As Ian Lustick (2000) nicely puts it:

Difficulties of amassing and manipulating collective identity data into theoretically potent comparisons are among the reasons that agent-based modeling can play an important role in the elaboration, refinement, and testing of the kind of specific and logically connected theoretical claims that constructivists have been faulted for not producing. Because the models are run on computers there is no room for ambiguity in the specification of the model's underlying rules.

This statement describes precisely what this paper aims at, although it is important not to interpret the reference to theory testing too literally. For while it is easy to generate unlimited amounts of "data" with a simulation model, such information should not be confused with real-world evidence. Thus, computational modeling cannot serve as a fullfledged substitute for empirical research. Rather, agent-based models constitute artificial, and indeed simplified, worlds in which the plausibility and consistency of well-specified causal mechanisms can be evaluated in a context that is more complex than that of standard, rationalistic modeling tools, but still much simpler than the real world. Serving as a stepping stone between micro and macro analysis, such models can help untangle interacting mechanisms, that together generate the phenomenon to be explained. This perspective defines a generative research strategy that starts from such patterns and moves backward in the search for candidate mechanisms that could generate observed outcomes (Cederman forthcoming).

In our case, the main pattern to be reproduced is constituted by the statistical findings that rebellions in weak states and mountainous areas are more frequent than elsewhere. What would it take to construct a set of plausible, predominantly identity-based mechanisms that generate such findings without resorting to the materialist explanations? As indicated in the previous section, any reconstruction of this kind must specify a process of identityformation that creates center-periphery relationships within which political action unfolds, in some cases with civil war as the outcome.

As a minimum, such configurations feature the following building blocks:

- Political organizations. The main protagonists are the sovereign states, whose centers dominate their peripheries.

- Terrain. Interaction has to proceed in a realistic space with obstacles, such as mountains and other types of rough terrain.

- Cultural map. Identity formation presupposes a multi-dimensional substrate of cultural traits.

- National identities. Nationalist behavior requires identities, which are constituted as combinations of cultural traits.

Needless to say, a model that comprises all these components would have to be complex. In fact, no existing model combines all these properties in the same framework. Most computational models of cultural politics make no distinction between culture and identities, thus violating a fundamental tenet of constructivist theory. Typically, culture is modeled as fixed and immutable properties influencing behavior (Epstein 2002) or as endogenous vectors whose traits all matter (Axelrod 1997, Chap. 7). Identities, however, are more selective, because only relevant culture enters the political calculus. Allowing for such variation, Lustick's $(2000 ; 2002)$ ABIR system features endogenous identity repertoires composed by sets of identities, but the component identities stand in no specific relationship to each other and thus do not describe a coherent cultural space. 
Moreover, this, and almost all other models of this type, fail to provide an explicit representation for formal political organizations or terrain.

Inspired by Bremer and Mihalka's (1977) pioneering computational research in International Relations, I have developed a modeling architecture, called Geosim, that is better suited to solve the research problem studied in this paper (Cederman 1997). ${ }^{3}$ Embedded in a dynamic state system constituted by formal political organizations, it contains a constructivist logic that captures the culture as a tunable attribute space, with identity mappings as schemata based on this substrate (Cederman 1997: Chap. 8; 2001; 2002a). Once having generated national identities of the centers and peripheries, these can be brought to bear on behavior, thus avoiding cultural determinism. What is missing here, however, is a representation of rugged terrain. The current model thus needs to incorporate a topological map beneath the cultural and political representations. Fortunately, I have already developed a module of this kind for a different purpose (Cederman 2003b). It would seem that a complex model that includes all these dimensions would do a better job at formalizing Rokkan's comprehensive centerperiphery logic than any other existing framework.

In macro-historical theorizing, it is impossible to circumvent the question of where to start. Strictly speaking, the contingency of world history forces us to depart from the dawn of human history. Yet, such a research design would be obviously impractical. Instead, I propose a telescoped, staged process that attempts to combine dynamics at different time scales. Complex systems are known to contain processes operating according to vastly different time tables (Simon 1981; Braudel 1980). While sometimes lasting for a long time, civil wars typically outpace nation-building. National identities, in turn, emerge much faster than the cultural systems within which they are situated.

In order to reduce endogeneity to manageable proportions, the staged design starts with the most slow-moving processes and then shifts the focus to faster dynamics. As the faster-moving phases are added, the configurations resulting from the previous phases are held constant. This facilitates the design and calibration of the framework as well as the tracing of causal pathways unfolding during each stage.

More precisely, the current model comprises four phases, each one corresponding to a distinct set of historical processes: ${ }^{4}$

\section{Phase I: Initialization}

The first stage initializes the model by generating three of the main ontological building blocks, namely a state system, a representation of terrain, and a cultural landscape, all embedded within a square grid. These basic entities are parametric and result from algorithms that make no claims to achieving realism in terms of the dynamics of the system. The parametric nature allows the experimenter to retain full control over the configuration of each component.

First the initialization routine generates a geographic map that allocates a altitude to each cell in the grid up from zero to maxheight $=3$. Initially, a tunable number of mountain peaks are distributed randomly across the grid. Then a diffusion process connects these peaks with their surrounding sites, thus creating relatively smooth mountainous terrain

\footnotetext{
${ }^{3}$ Whereas my first models were based on Pascal, in more recent years, I have relied exclusively on Repast, the leading Java-based package for agent-based modeling in the social sciences, see

http://repast.sourceforge.net/. This is the first of my papers that have been run in a distributed environment developed by Luc Girardin.

${ }^{4}$ The parameter values mentioned in this section are the default values, some of which will be varied in the section on sensitivity analysis.
} 
gently sloping down to the plains. Later the heights will be used as weights slowing down interactions between the center and the periphery (see the Appendix for details).

Second, a state system, equipped with a tunable number of states, here 30 , is created. Again, the algorithm starts by randomly allocating the same number of sites, from where a recursive process proceeds by absorbing the surrounding provinces. This accelerated process of geopolitical consolidation is slowed down in mountainous areas, which means that the state borders will respect geographical obstacles at least to some extent. Note that this process is a simplified and drastically compressed version of the more realistic series of conquest in the second phase of this model (see also Cederman 2003a).

[Figure 1 about here]

Figure 1 shows the standard $30 \times 30$ grid. Its cells have their own altitudes, which together constitute mountain chains in gray shades, with darker shades corresponding to the most rough areas. In this case, a large part of the grid is mountainous. On top of this geographic map, thirty sovereign states reside, with the black lines corresponding to their borders and the circles to their capitals.

Finally, the initialization phase produces a cultural map that is a multi-dimensional grid allocating a symbol string to each site of the grid. The algorithm orchestrates a simulated "age of migrations". As in the previous types of maps, this one starts with a selection of random locations, this time corresponding to the homeland of each ethnic community. Each of these ethnic communities is allocated an entirely stochastic symbol string, such as $\left\{\begin{array}{lllllllll}2 & 3 & 1 & 4 & 4 & 2 & 2 & 2\end{array}\right\}$ with eight traits and four possible values. Two parameters drive this process: the number of ethnic groups numethnies $=5$ that participated in the cultural settling of the landscape and the culturalDrift $=0.1$ parameter defining the cultural differences within each tribe's territory. This process, which is also affected by geographic obstacles, guarantees that there will be both dialectal nuances as one moves from province to province as well as more abrupt ethnic cleavages representing language, or even civilizational, borders.

[Figure 2 about here]

Instead of depicting geographical obstacles, the shading in Figure 2 portrays the cultural differences among the local sites. While the darker shading correspond to areas characterized by great cultural differences, the brighter ones refer to cultural "plains" in the cultural landscape. In our example, five randomly located ethnic groups fill the whole grid with a trait-by-trait drift of 0.1 . Overlaid on top of this cultural map is a simplified version of the geographic contours, coloring all areas of altitude above one unit in brown, semi-translucent shades.

\section{Phase II: State formation and assimilation}

The next phase operates as a geo-cultural "pressure cooker" at much slower speed than the first phase (see the Appendix 1 for details). First, because the initial stage does not guarantee that the states are even remotely geopolitically viable, it is important to expose them to some internal and external competition. Once unleashed, the sovereign states will start interacting locally with their immediate territorial neighbors and with their own provinces. This means that both interstate wars and secession can happen, although the latter is less likely because the would-be rebels cannot resort to nationalist coordination as in Phase IV.

Interaction can be of two types: either the actors peacefully exist side by side or they engage in combat. As explained in the Appendix, conflict is initiated according to a 
simple decision rule, which depends on the local power balance between the two parties (see also Cederman 2003a). Roughly speaking, the actors play a "grim trigger" strategy with another. This means that they normally reciprocate whatever their neighbors did to them on their respective fronts. But whenever the power balance in their favor exceeds a preset, stochastic threshold that governs the offense dominance of the system, they launch unprovoked attacks.

Assuming that interactions among states unfold as conventional battles with clearly marked defense lines, I put the attacker's threshold at 2.5. In internal conflict, however, the threshold is set to one, because in insurrectional fighting, it is less likely that there are fixed defense lines requiring the aggressor to be decisively superior. In these cases, only the provinces engage in unprovoked attacks, and then always with the aim of breaking out of the state. Yet, the capitals always fight back should there be an insurrection.

Identical stochastic criteria govern the outcome of battles. In interstate wars, a victorious attacker is allowed to absorb the province fought over. If the defending state wins, however, the status quo results. Civil wars always end in secession if the break-away province prevails, otherwise there is no change of the geopolitical map.

Rather than being driven by an advanced, trade-based economy, the system is animated by a primitive resource metabolism based firmly on territory with some stochastic noise added to the extraction process. Crucially, the centers' resource extraction declines as a function of effective distance discounting for terrain obstacles. Even on a plain, transportation incurs cost per distance unit. In the mountains, however, moving through each site adds a logistical penalty proportional to the altitude of the area. If the altitude is three, for example, the effective distance ends up being three rather than one.

[Figure 3 about here]

It is convenient to model the logistical constraints with a loss-of-strength gradient (Boulding 1963; Gilpin 1981). Figure 3 displays such a logistical curve, which slopes gently from $100 \%$ extraction at zero distance from the capital down to $30 \%$ at large distances. This function also governs power projection of all actors. This is especially important, because it becomes difficult for the governments to fight far away from their capitals, especially in rugged terrain. The provinces, however, never have to worry with terrain discounting, because all of their power extraction and power projection occurs "at home." As we will see in Phase IV, this important asymmetry helps fuel rebellions.

In addition to wars and secessions, this phase also features assimilation by the capitals to their own cultural makeup. Note that though both the political and cultural maps produced by Phase I are both influenced by geographical conditions, they are not directly connected. Yet, throughout the ages, states have had more or less impact on their cultural makeup of their populations. The assimilation process, introduced in the phase, proceeds by allowing each capital to assimilate one cultural trait of a province with a constant probability per "visit" (see the Appendix). In our test run, we will let the assimilation rate assimil be 0.01 only, which means that 1000 time periods do not suffice to iron out all differences.

[Figure 4 about here]

The result of geo-cultural change can be inspected in Figure 4. At the end of this period, i.e. at time step 1000, three of the smallest states in Figure 2 have disappeared leaving behind them a few two-unit fragments. Otherwise, the state system looks very much like it did at the beginning of the phase, thus reflecting the evolutionary stability of the 
surviving states. In terms of culture, there are more important changes. Although the rate of assimilation is quite low in this case, the sharp "civilizational" differences have been partly smeared out. This can be seen clearly in the state in the lower right corner of the grid. The capital has managed to iron out some of the cultural "ruggedness," but far away from the capital, it remains mostly intact.

\section{Phase III: Nation-building}

Once having created a plausible geo-cultural environment, we are ready to introduce national mobilization. Rather than treating nationalism as a constant "law", I model the phenomenon as a macro-historical process that emerges exogenously in the entire system at a specific point in history. This point occurs at time step 1000 and the process of nation-building continues for another 200 time steps.

In keeping with the staged research design, I freeze all previous social configurations, including the state system and the culture map, assuming that they represent slow-moving changes that can be treated as exogenously. This means that no interstate warfare or secession can take place from this point. ${ }^{5}$ Furthermore, at this point, assimilation ceases to operate as well. This allows us to focus entirely on national identity-formation in a stable geo-cultural framework.

In designing the nationalism part of the model, I have striven to stay as close as possible to modern, constructivist theories of nationalism (Cederman 2002b). Most importantly, this modeling extension introduces a fundamental distinction between the underlying cultural landscape and the national identities as political coalitions. Although the attribute space has an impact on identity formation, there is no one-to-one correspondence between culture and national identities, because only politically relevant traits count in national identity-formation.

Fortunately, there is a computational solution to this conceptual problem as well. In an attempt to formalize sets of symbol strings to be used in "schemata" representing rules, John Holland (1995) introduces wildcards (\#) for those traits that could be of any value (Cederman 1997, Chap. 8; 2001; 2002a). For example, the string $\{4 \# \# 23 \#$ \#\# represents an identity template (see the Appendix for details). It is convenient to represent national identities in a similar way. Let us assume that nations form as "imagined communities" in the public domain and that states could become members of them as long as their culture strings match them. These constraints generate a hypothetical feasible set of identities to which a given actor could belong. It remains to be described how the actual selection occurs.

National identities are represented as distinct groups to which any state or province can belong if the nation's identity fits the actor's own culture. While both capitals and provinces are eligible members of nations, the probability of launching a nationalist movement depends crucially on the geopolitical status of the actor in question. Thanks to their cultural and material resources, capitals have much higher chances of founding their own nations, but provinces may sometimes create distinct nationalist platforms in opposition to their respective capitals. The likelihood of joining an existing nation, however, is quite high, reflecting the lower difficulty of such an identity selection. In addition, all mobilized actors, whether provinces or capitals, attempt to recruit new

\footnotetext{
${ }^{5}$ This simplification is strictly motivated by the research design rather than by the model's ontology. In reality, these geopolitical processes can be expected to be heavily influenced by the onset of nationalism (Cederman 2001; 2002a). Fortunately, the model allows for simultaneous, co-evolving processes. This is an obvious extension to which I hope to return in future research.
} 
members to their identities by visiting neighboring sites, discounted by the terrain roughness. Once mobilized, an actor never loses its national identity.

[Figure 5 about here]

Showing the grid at time 1200, at the end of the nation-building phase, Figure 5 displays the national identities as colored disks, complemented with a number beneath each disk corresponding to the respective nation's index number. It is clear that most capitals have already become nationally mobilized. In several cases, national communities spill over state borders. For example, three capitals shares the same nation on the right-hand side of the grid. The two right-most of these states have very few minorities.

Notice that nearly perfect nation-states appear in the plains. The mountainous regions, in contrast, offer less hospitable conditions to nation-builders. The state whose capital belongs to nation 14, for example, is clearly multi-national, because apart from four members of that nation including the capital, there are also six members of nation 3 and one member of nation 22. As we will see in the next phase, such differences influence the likelihood of civil wars.

\section{Phase IV: Civil war}

Focusing on internal conflict, the final phase of the model pits provinces against capitals while freezing everything else, including the national identity-formation process of the previous phase. This means that national identity configurations and the states' outer borders have to remain intact. Culture no longer has any direct impact on the behavior of the model. Having ruled out interstate wars and secession, only rebellions are allowed to happen. Whether the capital or the province prevails, the status quo results, and the rebels are allowed to regroup.

It may seem that this exogenization unduly restricts the analysis, but it makes some sense for the period following 1945. With the very important exceptions of imperial collapse associated with the decolonization process and the disintegration following the end of the Cold War, secession has been a relatively rare event in world politics (see e.g. Hechter 1992), especially in post-colonial Africa (Herbst 1989). Likewise, as already noted, there have been few interstate wars as well.

It is now finally time to introduce the rules governing outbreaks of civil wars. In fact, this phase retains the mechanism that governs secession attempts in Phase II, though without the geopolitical consequences. While obviously fought interactively between the centers and the peripheries, such conflicts can only be initiated by the provinces in this version of the model. Still, it is assumed that the capitals fight back if attacked. The previous domestic decision-making threshold at one (rather than 2.5) operates in this phase as well. The main difference pertains to the resource calculation of the mobilized provinces. Once belonging to a nation, a province will attempt to recruit nationalist support from other co-national provinces within the same state. The potential rebel organizes such recruitment campaigns before deciding whether or not to attack the capital. Controlling how many of the nationalists that feel obliged to help their kin, the parameter natoblig determines the stochastic proportion of success in such cases. After adding up the resources of the potential coalition, the province in question is more likely to trigger a civil war, because thanks to nationalist solidarity, the balance can shift more decisively in favor of the periphery. With this logic in place, it is harder for the capital to "divide and rule" within its territory. 
If the leading province decides on action, all co-national units that pledged support will make good of their promise. ${ }^{6}$ Fighting on several fronts will force the capital to redistribute its resources, thus in many cases opening opportunities for other provinces to join the fray even if they do not belong to the same nation. In some cases, unmobilized actors, who could be bandits or other opportunistic rebels, may decide that the power balance has shifted so much in their favor that they also want to fight the capital.

Combat then proceeds according to the same rules as in Phase II. Depending on the local power balance for each center-periphery dyad either the capital or the province prevails. Who wins, and for how long the fighting lasts, is immaterial for the purposes of this paper, because as already stated, all geopolitical consequences have been inhibited for methodological reasons. What matters here is whether there is fighting at all or not.

[Figure 6 about here]

Figure 6 illustrates how all this works. At time 1239, civil wars rage in two states. Each local battle is marked by a red ring. In the state whose capital belongs to nation 14 at the top of the grid, two nation-3 provinces and two unmobilized ones have taken up arms against the capital. Likewise, at the bottom of the grid, the state with nation 5 as its official identity has also descended into warfare. Here two nation-7 provinces have taken the lead followed by a non-nationalist province.

This particular snapshot suggests that fighting happens predominantly in rugged terrain. Is this a recurrent pattern? To find out, we have to study the behavior of the model more systematically. Fortunately, agent-based modeling allows us to rerun history

counterfactually as often as we want (Cederman 1997, Chap. 3), and it is to this task that we turn in the next section.

\section{Replication results}

The telescoped histories constitute artificial worlds that can be subjected to controlled experiments. In this section, I apply standard statistical methods to the system as if it were real. To come as close as possible to conventional methodology, cross-national (or to be correct, cross-state) data need to be collected. Then I regress the simulated conflict outcomes on the states' determinants to find out how well alternative explanations fare. This approach allows us to assess what quantitative analysis would have told us had the model coincided with the real world. Note that the task of measurement is considerably easier in an artificial world, because there is no room for errors in a computational models. Moreover, thanks to the telescoped design, endogeneity becomes more manageable as well.

The research design is simple. For each parameter configuration, 30 runs are executed. The replications are based on ten randomly generated geographical maps with their associated state systems as in Figure 1. For each such configuration, the model is run with three independently generated cultural maps. ${ }^{7}$ Measurement proceeds during Phase IV, which lasts from time step 1200 through step 2200. The number of observations amounts to almost 900, because there are about 30 states in each of the 30 runs (excluding unitary ones). Regressions are run on all of these observations in a pooled sample. Data for the following variables are collected for each (non-unitary) state in each run:

\footnotetext{
${ }^{6}$ This is obviously a questionable assumption that needs to be endogenized (see Gates 2002).

${ }^{7}$ This is achieved through a separation of the stochastic processes, so that the cultural mechanisms rely on random numbers drawn from a separate generator that is seeded apart from the main seed.
} 
- The dichotomous dependent variable civilwar is set to one if at least one centerperiphery battle occurred within the territory of the state in question throughout Phase IV, otherwise the variable remains zero.

- The first independent variable strength holds the resource level of each state.

- The second independent variable height measures the average altitude of the state in question based on the capital and all provinces.

- The third independent variable numnat counts the number of peripheral nationalist provinces that are holding a different national identity than the capital (or any national identity if the capital is unmobilized).

- The fourth independent variable natdist reveals the average terrain-corrected distance from the capital of all the oppositional nationalist provinces if there are any, otherwise the variable is set to zero.

Whereas the two first independent variables tap materialist properties of the states, the two last ones capture cultural determinants relating to national identities. It is therefore possible to separate materialist from identity-based hypotheses.

Let us start by considering what one would expect from a rationalistic perspective. The hypothesis would be that the two first, materialist variables should be significant, while the cultural ones should be immaterial. After all, Fearon and Laitin (2003) find GDP per capita, interpreted as a proxy of state strength, to be a strong predictor of internal conflict. Moreover, their theory of insurgency also implies that rough terrain explains civil wars.

In opposition to this view, a relationist interpretation inspired by Rokkan would lead us to anticipate the last two variables to have a strong impact independently of the power of the materialist ones. First of all, the stronger the nationalists are in general, the better their chances to rebel. Note that this crude measure is not necessarily the same things as the overall ethnic fractionalization of a state. Rather it captures the overall power of any oppositional nationalists within a state. ${ }^{8}$ Second, as suggested by Weiner's (1978) "sons of the soil" mechanism, it is not merely the average ruggedness that matters, but more specifically whether the peripheral nationalists can take advantage of rugged terrain in their struggle against the center. Thus, the location of the groups is central in this mechanism. From this perspective, Fearon and Laitin's (2003) explanation is too shallow, because it fails to take into account that identity-formation may also be correlated with topological conditions, and consequently the settlement patterns assume crucial causal importance.

\section{[Table 1 about here]}

To assess which perspective prevails in our simulations, I run multivariate logit regressions while varying natoblig, which measures the effectiveness of nationalist mobilization. Table 1 lists the results from regressions that only include the logistical variables strength and height. The middle panel corresponds to a $50 \%$ rate of recruitment success in the nationalist campaigns (natoblig $=0.5$ ), which is the default value that

\footnotetext{
${ }^{8}$ Given the specification of the model's micro-level mechanisms, this is far from a perfect indicator of civil war. A better one would be to measure the resources of the strongest national identity within each state. In this paper, I am merely focusing on the logic of nationalist mobilization rather than on nationalist coordination (for the latter, see Cederman 1997, Chap. 8).
} 
what we used in the sample run shown so far. In the upper and lower panels natoblig is set to 0.1 and 1.0 respectively. The table reveals that both variables are strongly significant, even though the effect of strength declines somewhat in the systems that are the most nationalist but remains strongly significant. Purely based on this data, political economists would be forgiven for believing that their theories suffice to account for the behavior of this model

[Table 2 about here]

However, this picture changes drastically when nationalist mobilization is controlled for. Table 2 makes clear that the constructivist variables numnat and natdist account for much of the variation in conflict behavior regardless of the effectiveness of nationalist recruitment. As would be expected, the number of peripheral nationalists numnat has a stronger impact on the dependent variable the higher the value of natoblig. The nationalists' distance from the capital, captured by natdist, also matters strongly, though here the impact declines somewhat with the effectiveness of nationalist mobilization.

Interestingly, the effect of the materialist variables remains pertinent. In fact, the strength variable becomes even more pertinent both in terms of its impact and its significance. The height variable, in contrast, is weakened in both respects, although it remains significant when nationalist mobilization becomes more effective.

In view of these findings, it is clear that statistical accounts of the system that incorporate the right identity-related variables perform better than those that fail to do so. We already know that a lot happens in the model that cannot be reduced to materialist logistics. But is this "meta finding" robust beyond variation in terms of natoblig? To find out, the next section presents a preliminary sensitivity analysis.

\section{Sensitivity analysis}

Although a more thorough analysis would have called for a combinatorial sweep of parameters, this section varies one variable at a time. Thus I keep the default settings of the sample run illustrated in the previous section (with natoblig $=0.5$ ). Going back to the telescoped logic of the simulation runs, it is important to alter variables belonging to all phases. This procedure will establish confidence in the robustness of the findings across radically different time scales. In fact, Table 1 shows us that the cultural variables remain significant despite one type of manipulation of Phase IV (though it may obviously be sensitive to changes along other dimensions). Let us now consider each of the other phases in turn, starting with the most fundamental one.

\section{Variations in Phase I}

Empirical scholars can only dream of manipulating environmental background factors, such as terrain. Yet, in an artificial world, it is just as easy to alter the altitude and shape of mountain chains as it is to change one individual's behavior. Thus, the first sensitivity test entails "lowering" and "elevating" the mountains by running simulations where the maximum height is one and five rather than three, as in the default system.

\section{[Table 3 about here]}

Table 3 presents the findings of this exercise. It becomes immediately obvious that the two cultural variables remain robust, whereas only state strength of the materialist ones holds across the test values. As would be expected, reducing the geographic obstacles turns the height variable totally insignificant. 
Having studied the effect of changes in the terrain, it is now time to introduce variation in the structure of the initial cultural map. This is done along two dimensions. First, I vary the number of ethnies populating the initial grid. Second, I experiment with the rate of cultural drift, which determines the gradual, village-to-village cleavages.

[Table 4 about here]

[Table 5 about here]

Tables 4 and 5 suggest that such variations make almost no difference. This especially holds for the number of ethnic groups. The default system only has five of these, so I show results with 10 and 20 groups. It is impossible to detect any major difference between these replications: all variables are still strongly significant. Much the same applies to Table 5, though some trends occur when cultural drift is increased from 0.05 to 0.2 through the default value 0.1 . It appears that the natdist variable loses some impact in favor of the height variable as the control parameter is tuned upwards, but the shift is quite small.

\section{Variations in Phase II}

Having found the main results quite robust to alterations of Phase I, we now proceed to Phase II, where assimil, the rate of state-led cultural assimilation, plays the main role. What happens if we tune this parameter down to zero from the default value of 0.01 ? Will there be any change should this value be set to 1.0? Table 6 has the answers to these questions.

\section{[Table 6 about here]}

This time the behavioral output changes more as a result of the experimental manipulation. Given that the default value is quite low, removing assimilation matters less than accelerating the process to its maximum speed. It should be recalled that the latter value produces a cultural "level playing field" within the states, with virtually no deviations from the capitals' culture. Such flat cultural landscapes make for more homogeneous, and thus less violent, domestic politics. As a consequence, civil wars become extremely rare, which helps explain the lower significance of the estimates in this case. Despite this fact, the cultural variables remain the most robust, but even they lose some explanatory power as the assimilation reaches its maximum value. Again, the height variable becomes insignificant, most likely at the expense of natdist.

\section{Variations in Phase III}

The final step of our sensitivity analysis concerns the nation-building phase. I have chosen to control the minNumTraits parameter, which determines the national identities' "thickness." This variable stipulates how many symbols rather than wildcards a national identity needs to hold to be valid. The lower this value, the more inclusive the identity, which should make nationalist mobilization easier. Yet, this applies to both centers and peripheries, so it is not obvious what to expect.

\section{[Table 7 about here]}

In fact, deviations from the default value minNumTraits $=4$ seem to matter little, as shown by Table 7 . There is some variation in the estimates of the numnat coefficient, but the significance remains very solid despite the changes.

It appears that the main findings are able to survive a series of robustness tests. In the absence of a more thorough, combinatorial sensitivity analysis, I thus conclude on a 
preliminary basis that, at least, the results are far from knife-edge. Both materialist and identity-related variables retain their impact across the board, with a partial exception for height, which suggests that the average ruggedness of a country may be too blunt an indicator.

\section{Conclusion}

What are the theoretical lessons to be drawn from this paper? Given its somewhat unconventional nature, it is appropriate to start by stressing what it does not purport to say. First, I do not claim to have refuted rationalist theories of civil wars. It deserves to be reiterated that the statistical analysis shown above relates to an artificial world, and certainly not to real-world evidence. In fact, I offer no more micro-level validation than do most political economists, who also advance untested (but testable) theoretical interpretations. Second, nor do I argue that the current model offers the best formalization of relational theories of national insurgencies. After all, this is the first model of its kind. To my knowledge, geography and identity formation have never been investigated together in an integrated, dynamic model. Thus, I ask for the reader's patience with the sometimes drastic simplifications introduced.

Indeed, it is easy to think of important extensions of the model that could bring it closer to historical sociology and the empirical record itself. One of the most urgent tasks would to let political and cultural boundaries co-evolve (Cederman 2002b). This can be done within the current computational framework (Cederman 2001; 2002a). Both qualitative and quantitative studies have shown convincingly that ethnic conflict has a tendency to spill over state borders due to irredentism and other diffusion effects (Weiner 1971; Sambanis 2001; 2003). Yet, sometimes one step backward may mean that we can take two steps forward in the future. Despite this obvious loss of realism, the telescoped, phased design of the model introduces a powerful way of handling drastically different time scales without getting swamped by endogeneity.

Another part of the model that calls for elaboration is the behavioral interaction between the center and the periphery. The current specification lets the provinces take the lead, but this obscures an often delicate strategic "dance" going back and forth between the main protagonists, which features prominently counter-insurgency initiatives on the part of the capitals. Moreover, the current design stresses opportunity structures rather than actual motivations. Rational-choice theory offers many cues about the microfoundations of internal conflicts that could be integrated into the current computational framework (see e.g. Gates 2002). Nor is any claim to realism made as regards the clustering of fighting into civil wars, the frequency and duration of which can be validated empirically. More realistic strategies, together with cluster-finding algorithms, could facilitate such measurements, as illustrated by Cederman (2003a) in case of interstate wars.

Having stated what this study does not say, I owe the reader a few words about what I believe to be the actual consequences for future research. Most importantly, I hope to have discouraged students of civil wars from drawing too far-reaching inferences from political-economy studies like Fearon and Laitin (2003). While micro-level interpretations of macro-level data are indispensable to most explanations, the current paper illustrates that such mechanisms do not have to be rationalistic in the political economists' sense. Moreover, it should be clear that a model with a powerful geo-cultural logic as the one proposed here produces results that, at the surface, are very hard to separate from the expectations of rationalist scholars.

More specifically, two of the Fearon and Laitin's (2003) key variables, namely state strength and rough terrain, seemingly vindicate their logistical theory of insurrections. If 
properly measured, however, mechanisms of nationalist identity-formation may turn out to be correlated with materialist explanations. The computational model offers guidance as to how these mechanisms could be disentangled conceptually. However, the crux is that, while this is easily done in a computational model, it is much harder to carry out empirically. The political economists' statistical controls for "nationalism theory" often fail to grasp the logic of these alternative perspectives, partly because the theories to be refuted are too general, and partly because the macro-level indicators are inappropriate. There is therefore an acute need for better articulated theories of nation-building.

The main goal of this paper has been start closing this gap by articulating candidate mechanisms that can be more readily exposed to empirical tests. For sure, we still have some way to go both empirically and theoretically before a close match can be achieved, but I would submit that the current paper at least reduces the gap. Fortunately, thanks to the considerable interest that civil wars are attracting, new data are constantly made available, especially at the micro level. I have already mentioned Sambanis' (2001) systematic series of case studies, Sambanis and Zinn's (2003) new data base focusing on center-periphery interactions, and Gates and Buhaug's (2002) efforts to use geographic data to pinpoint the exact location of conflict. It would be very helpful if the conflicting parties could be geographically located as well, especially in relation to existing communication infrastructures.

Adding a new tool to our toolbox in the study of civil wars, model building of the type introduced by this paper will help relationist theorists sharpen their hypotheses and test empirical indicators in methodologically underdeveloped areas that have so far escaped the grasp of conventional approaches. Fortunately, thanks to their "colonization" of the literature on civil wars, the political economists have raised the explanatory bar considerably. Now the main task is to prevent this methodological leap forward from leading to premature theoretical closure. After all, much is at stake not merely scientifically, but also in terms of policy making. While factoring in macro-processes may seem defeatist from a policy perspective, it is more likely to lead to more realistic expectations about what is politically feasible in the short run, and what is not. Failure to see this difference may have serious consequences, as illustrated by the difficulties posed by "nation-building" in post-war Iraq. In an era characterized by ambitious democratization projects across the globe, historical ignorance and cultural "colorblindness" are likely to worsen the problems of ethnic violence and terrorism already haunting the world's most troubled neighborhoods. 


\section{Appendix: Technical notes on the model}

A variable-size grid constitutes the Geosim's core. Constituting the basic unit of the framework, a primitive actor reside permanently in each square of the grid. They can never be destroyed, but they do expand territorially and can also lose their sovereignty as other actors come to dominate them hierarchically.

All actors, whether primitive or compound, keep track of their geopolitical context with the help of a portfolio holding all of their current relationships. These can be of three types:

- territorial relations point to the four territorial neighbors of each primitive actor (north, south, west, and east).

- interstate relations refer to all sovereign neighbors with which an actor interacts.

- hierarchical relations specify the two-way link between provinces and capitals.

The behavior of the geopolitical base model depends crucially on these three types of relationship. Whereas all strategic interaction is located at the political level, territorial relations become important as soon as structural change happens. Combat takes place locally and results in hierarchical changes that will be described below.

The assumption that provinces retain relations only with their capitals represents a strong idealization of sovereignty in that the subordinate units cannot have political relations with other provinces or foreign actors. This simplification rules out the possibility of civil wars among the provinces not involving the capital. Secessionist civil wars between a capital and a province can occur, however.

As in my previous models, the logic of execution is quasi-parallel with double buffering (Cederman 1997). As opposed to picking one actors at a time and giving it all the "limelight", the process follows stages in which each actor executes code (cf. Cusack and Stoll 1990). To achieve quasi-parallel execution the list of actors is scrambled each time structural change occurs. The actors keep a memory of one step and thus make up an advanced Markov process (though with varying transition probabilities).

In the following, technical notes will be provided on each of the four phases, supplementing the specification given in the main text:

\section{Technical notes on Phase I}

The text above describes most of the details pertaining to the initialization routines of the geographical, political, and cultural configurations. However, a few additional notes on the first of these are in order. First, the terrain module allocates heights to every cell in the grid up to maxHeight $=3$. The algorithm starts by creating a random selection of mountain summits constituting a fraction propsummits $=0.05$ of all unitary cells. Then a recursive algorithm is run repeatedly 20 times smoothening the height of the surrounding cells. This "brush" continues to a cell in the von Neumann neighborhood with a probability of 0.8 . For each "visit", the algorithm sets the neighboring call to a weighted average 0.7 of the initial cell and its previous value. From an intuitive standpoint, this algorithm is similar to water flowing from the mountain peaks dragging with it soil that leads to a smoother landscape around the summits.

\section{Technical notes on Phase II}

The main simulation loop of Phase II contains six steps that will be presented in the following. In the first phase, assimilation takes place. Second, the actors update their resources. Third, both capitals and provinces allocate these resources to their fronts. Fourth, a decision procedure follows, during which they decide on whether to cooperate or defect in their neighbor relations. Fifth, the interaction phase determines the winner of 
each battle, if any. Sixth, the structural change procedure carries out conquest and other border-changing transformations.

Step 1. Assimilation

During each time step, with a probability of assimil $=0.01$ each compound state gets the chance to assimilate each one of its provinces. A trait of the province's culture string is selected randomly and set to the same value as the capital's corresponding cultural trait. If the traits are already the same, no change is effected.

Step 2. Resource updating

As the second step in the actual simulation loop, the resource levels are updated. The simple "metabolism" of the system depends directly on the size of the territory controlled by each capital. It is assumed that all sites in the grid are worth one resource unit. A sovereign actor $i$ begins the simulation loop by extracting resources from all of its provinces. It accumulates a share of these resources determined by a distance-dependent logistical function dist (see Figure 3 above):

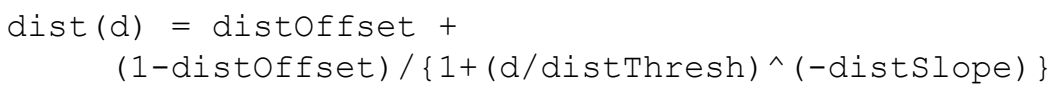

where distoffset $=0.3$ sets the flat extraction rate for long distances, and distslope $=$ 3 the slope of the curve (higher numbers imply a steeper slope) and distThresh $=5$ the threshold value of the curve. Based on this logistic curve, the tribute gained from each province is discounted in proportion to the province's geography-corrected distance $d$ from the capital. The resources of the actor res $(i, t)$ can now be computed by adding the non-discounted resources of the capital together with the sum of all tribute from the provinces. Then some normally distributed noise is added, with a standard-deviation resSD $=0.02$ times the resource level. Finally, the resources res $(i, t)$ of actor $i$ in time period $t$ can be computed by factoring in the new resources multiplied by a fraction reschange $=0.5$ :

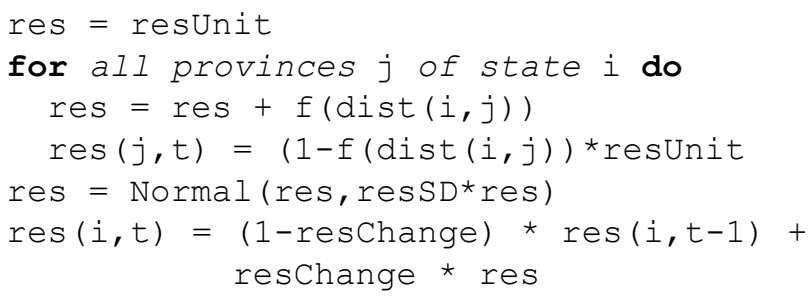

Step 3. Resource allocation

Before the states can make any behavioral decisions, resources must be allocated to each front. For unitary states, there are up to four fronts, each one corresponding to a territorial relation (those located in the corners of the grid have a few as two neighbors). Resource allocation proceeds according to a hybrid logic. A preset share of each actor's resources are considered to be fixed and have to be evenly spread to all external fronts. Yet, this scheme lacks realism because it underestimates the strength of large actors, at least to the extent that they are capable of shifting their resources around to wherever they are needed. The remaining part of the resources, here propMobile $=0.5$, are therefore mobilized in proportion to the opponent's strength and the previous activity on respective front. The current model features a simplified version of Proportional Resource Allocation. Mobile resources are proportionally allocated to fronts that are active (i.e. where combat occurs will occur), but also for deterrent purposes in anticipation of a new 
attack. Resources are always allocated under the assumption that no more than one new attack might happen.

For example, a state with 50 mobile units could use them in the following way assuming that its two provinces control 10 and 15 units, and three neighboring states 20,25 , and 30 respectively. If the previous period featured civil war with the second province and interstate war with second of the neighbors, these two fronts would be allocated $15 /(15+25) \square 50=18.75$ and $25 /(15+25) \square 50=31.25$. Under the assumption that one more wars could start, the other province, and the remaining two states would be allocated respectively: $10 /(15+25+10) \square 50=10,20 /(15+25+10) \square 50=20$, and $30 /(15+25+10) \square 50=30$.

Formally, resource allocation for state $i$ starts with the computation of the fixed resources for each relationship $j$. A preset proportion of the total resources res are evenly spread out across the $n$ fronts:

fixedRes $(i, j)=(1-p r o p M o b i l e) *$ res $/ \mathrm{n}$

The remaining part mobileRes $=$ propMobile $*$ res is allocated in proportion to the activity and the strength of the opponents. To do this, it is necessary to calculate all resources that were targeted at actor $i$ :

$$
\text { enemyRes }(i)=\sum\{j\}\{\operatorname{res}(j, i)\}
$$

The algorithm of actor i's allocation can thus be summarized:

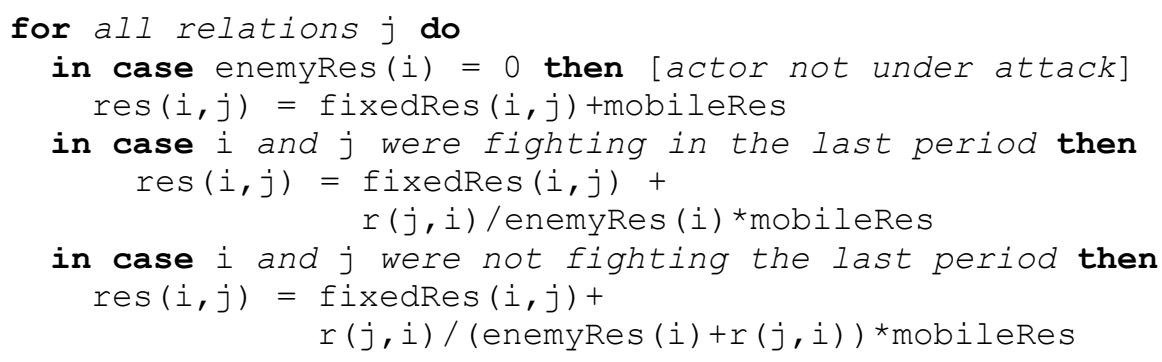

The provinces allocate all their resources to the front against the capital.

Step 4. Decisions

Once each actors has allocated resources to its external and possibly internal fronts, it is ready to make decisions about future actions. This is done by recording the frontdependent decisions in the corresponding relational portfolio. Since two-level action is allowed, both sovereign states and provinces execute their algorithms in each period. As with resource allocation, this happens in parallel (or to be more precise in randomized order) without any reference to other actors' decisions during the current time step.

All actors start by playing unforgiving "tit-for-tat" with all their neighbors, a strategy that resembles the game-theoretic strategy "grim trigger" in conventional iterated games. The power-seeking aspect of the strategy relates to the second step featuring an unprovoked attack provided that no combat is already under way. First a potential victim $j^{\prime}$ is selected.

Provinces only have one option: to attack the capital. Capitals, however, never launch an unprovoked attack against a province, but may well launch combat action against 
external enemies. The decision to attack depends on a probabilistic criterion to which we will return below. If an attack is approved, the aggressor chooses a battle path consisting of an agent and a target province. The target province is randomly chosen as any primitive actor of $j^{*}$ (including the capital) that borders on $i$. Also stochastically selected, the agent province is a province of $i$ (including the capital) that borders on the target.

In summary, the decision algorithm for sovereign states subscribes to the following logic:

Decision-rule of sovereign state $i$ :

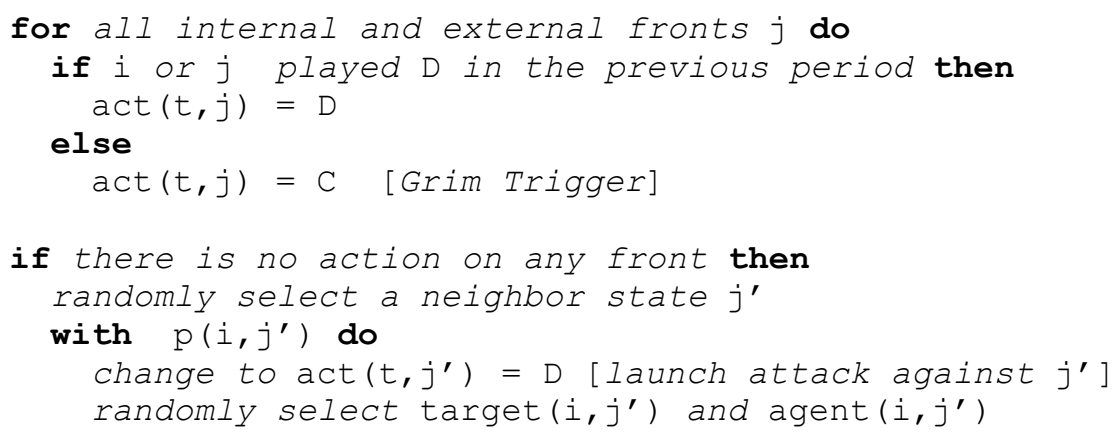

Since provinces have only one relationship to deal with, namely that with the capital, they use a simpler decision-rule:

Decision-rule of province $i$ with capital $j$ :

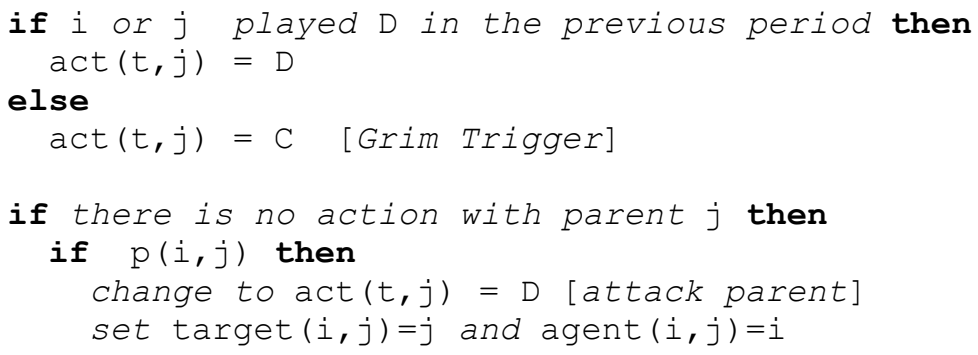

The precise criterion for attacks $p\left(i, j^{\prime}\right)$ remains to be specified. The model relies on a stochastic function of logistic type in which the local power balance plays the main role:

$\operatorname{bal}\left(i, j^{\prime}\right)=\operatorname{dist}(d) \star \operatorname{res}\left(i, j^{\prime}\right) /\left\{\operatorname{dist}\left(d^{\prime}\right) \star \operatorname{res}\left(j^{\prime}, i\right)\right\}$

where dist $(d)$ is the distance function described above and $d$ and $d^{\prime}$ the respective distance from the capitals of $i$ and $j$ to the battle site. This discounting introduces distance-dependence with respect to power projection. Hence, the probability can be computed as:

$$
p\left(i, j^{\prime}\right)=1 /\left\{1+\left(\text { bal }\left(i, j^{\prime}\right) / \text { supTresh }\right)^{\wedge}(- \text { supslope })\right\}
$$

where supTresh is a system parameter specifying the threshold that has to be transgressed for the probability of an attack to reach 0.5 , and supslope a tunable parameter that determines the slope of the logistic curve, which is set to 15 for the runs 
reported in this paper. Note that supTresh $=2.5$ for interstate interactions, and supTresh $=1$ for domestic conflict.

Step 5: Interaction

After the decision phase, the system executes all actions and determines the consequences in terms of the local power balance. The outcome of combat is determined probabilistically. If the updated local resource balance bal $\left(i, j^{\prime}\right)$ tips far enough in favor of either side, that side wins the battle. In the initial phase, the logistical probability function $q\left(i, j^{\prime}\right)$ has the same shape as the decision criterion with the same threshold set at victThresh $=2.5$ and with an identical slope: victslope $=15$ :

$$
q\left(i, j^{\prime}\right)=1 /\left\{1+\left(\operatorname{bal}\left(i, j^{\prime}\right) / \text { victTresh }\right)^{\wedge}(-\operatorname{victslope})\right\}
$$

This formula applies to attacks among capitals. In accordance with the strategic rule-ofthumb that stipulates, in interstate wars, that an attacker needs to be about three times more powerful than a defender to prevail, the threshold of the latter is set to $1 /$ victThresh. No such inversion is needed in civil wars because in those cases victThresh is set to one.

Each time-step of a battle can generate one of three outcomes: it may remain undecided, one or both sides could claim victory. In the first case, combat continues in the next round due to the grim-trigger strategy in the decision phase. If the defending state prevails, all action is discontinued. If the aggressor wins it can advance a territorial claim, which is processed in the structural change phase.

\section{Step 6: Structural change}

Structural change is defined as any change of the actors' boundaries. The current solution closely follows the mechanism introduced in Cederman (1997, Chap. 4). Thus structural change only affects one primitive unit at a time, and can thus be seen as a matter of territorial combat rather than a diplomatic game at the political level.

To render the system manageable, the underlying assumption governing structural change enforces states' territorial contiguity in all situations. As soon as the supply lines are cut between a capital and a province, the latter becomes independent.

The units affected by any specific structural claim are defined by the target $(i, j)$ province set in the decision phase:

- if target $(i, j)$ is a unitary actor, then the entire actor is absorbed into the conquering state,

- if target $(i, j)$ is the capital province of a compound state, then the invaded state collapses and all its provinces become sovereign,

- if target $(i, j)$ is a province of a compound state, then the province is absorbed. If, as a consequence of this change, any of the invaded states' other provinces become unreachable from the capital, these provinces regain sovereignty.

Secession works in a similar way. For each sovereign state $i$, the algorithm also goes through all of the provinces to see if any of them has raised a claim. If this is the case, the province becomes sovereign while retaining all its previous resources. Sometimes the independence of a province makes other provinces unreachable from the old capital, in which case these provinces are made sovereign as well. By contrast, if the capital advances a claim in the interaction phase, no structural change occurs, but the actions and memories are reset to $\mathrm{C}$ thus ending that particular secessionist attempt. 


\section{Technical notes on Phase III}

Reflecting the distinction between culture and nations, nations are implemented as independent computational objects with their own lists of members. A nation is born as soon as a state decides to create one. It is also possible to join or leave an already existing nation. Nations without members are deleted. A state can only be a member of one nation at a time. ${ }^{9}$

When a nation is created, its creator determines its identity based on the actor's own culture string. This is done stochastically by setting each of the nation's identity trait to the value of the creator's corresponding cultural trait with probability probTrait $=0.2$. If not set, the trait remains irrelevant and is marked by a "wildcard" \#. A total number of minNumTraits $=4$ have to be specified. This procedure is repeated until at least one of the traits becomes relevant. For example, if the creator has the culture string $\begin{array}{lllll}4 & 1 & 2 & 3\end{array} 3$

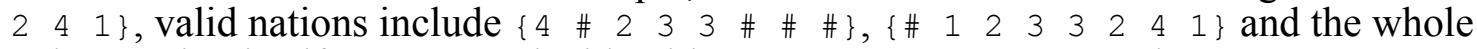

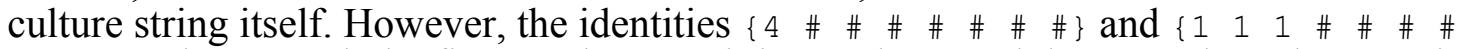
\# cannot be created, the first one because it is too short, and the second one because it does not fit.

An actor can join a nation if there is no incompatibility between the national identity's relevant traits and the actor's corresponding cultural trait. Thus, a state with culture $\left\{\begin{array}{l}4 \\ 1\end{array}\right.$

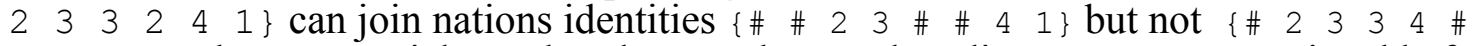
\# 2\}. Note that a potential member does not have to be adjacent to any co-national before joining. Nations, as opposed to territorial states, are predominantly ideational entities that can span over vast spaces without there necessarily being contiguity.

Nationalist mobilization hinges on the status of the primitive unit $i$, which may be a capital or a province. If it is not yet mobilized, parameterized probabilistic criteria govern the creation or joining of nations. Thanks to their resources, capitals are much more likely than other units to create new nations prCapitalcreateNation $=0.01$ than provinces, in which case the probability is as low as prCapitalcreatenation $=0.00001$. If these lowprobability events do not apply, the likelihood of a units joining an existing nation (to the extent that one exists with the right fit) is very high: prJoinNation $=0.3$. Should the unit in question already belong to a nation, it will attempt to recruit the immediate territorial neighbors. With probability prRecruitToNation $=0.3$, the unit in question will move to an adjacent site in its VonNeumann neighborhood and invite this primitive unit to join to the extent an identity fit exists. Here is a summary of the algorithm in pseudo code:

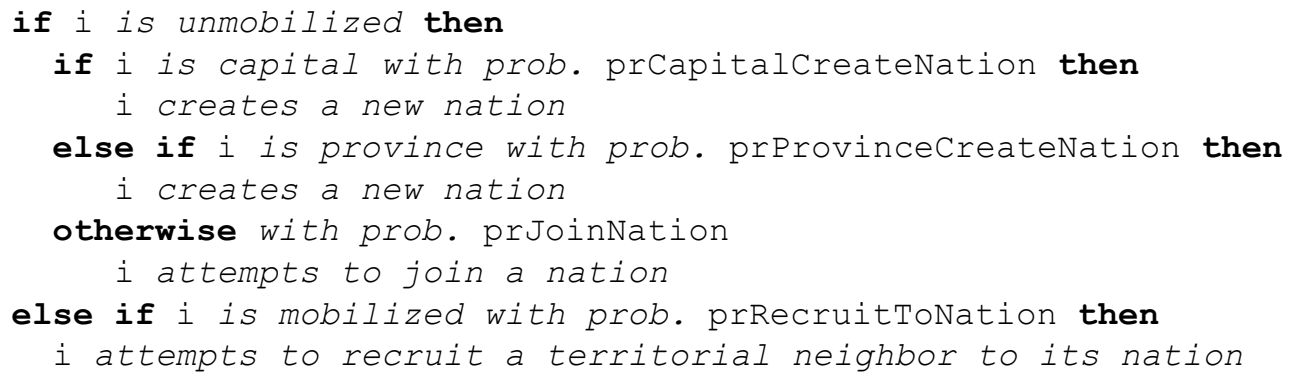

\section{Technical notes on Phase IV}

This phase features modifications in the behavior of the provinces, which are now able to form nationalist coalitions with nationalist kin provinces within the same state, as long as the capital does not belong to the same nation as the provinces in question. Nationalist

\footnotetext{
${ }^{9}$ For the time being, mergers and splits of nations are not supported but could be easily implemented.
} 
insurrections operate through a modified balancing mechanism, which facilitates the insurrectionists' search for a solution to the collective choice dilemma. If contemplating a rebellion, a province will attempts to recruit support. The probability of any other kinprovince's accepting such an invitation is prNatOblig $=0.5$.

The modified power-balance criterion for a possible attack by province $i$ against capital $j^{\prime}$ is:

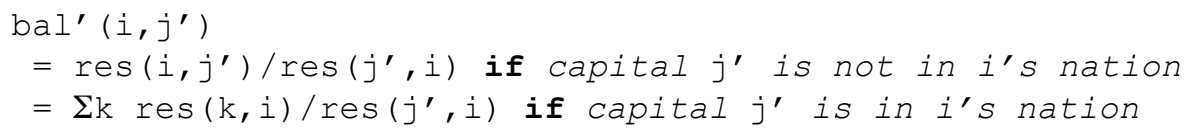

where $\square k$ res $(k, i)$ are the pooled resources of the nationalist coalition. All provinces that accepted the call make good of the pledge of fighting against the capital. 


\section{References}

Axelrod, Robert. 1997. The Complexity of Cooperation: Agent-Based Models of Competition and Collaboration. Princeton: Princeton University Press.

Boulding, Kenneth E. 1963. Conflict and Defense. New York: Harper and Row.

Braudel, Fernand. 1980. On History. Translated by S. Matthews. Chicago: The University of Chicago Press.

Bremer, Stuart A., and Michael Mihalka. 1977. Machiavelli in Machina: Or Politics Among Hexagons. In Problems of World Modeling, edited by K. W. Deutsch. Boston: Ballinger.

Buhaug, Halvard, and Scott Gates. 2002. The Geography of Civil Wars. Journal of Peace Research 39 (4):417-433.

Cederman, Lars-Erik. 1997. Emergent Actors in World Politics: How States and Nations Develop and Dissolve. Princeton: Princeton University Press.

Cederman, Lars-Erik. 2001. Nationalist Systems Change and its Geopolitical Consequences. Paper presented at the Annual Convention of the American Political Science Association, San Francisco.

Cederman, Lars-Erik. 2002a. Endogenizing Geopolitical Boundaries with Agent-Based Modeling. Proceedings of the National Academy 99 (suppl. 3):7796-7303.

Cederman, Lars-Erik. 2002b. Nationalism and Ethnicity. In The Handbook of International Relations, edited by W. Carlsnaes, T. Risse and B. Simmons. London: Sage.

Cederman, Lars-Erik. 2003a. Modeling the Size of Wars: From Billiard Balls to Sandpiles. American Political Science Review 1 (97):135-150.

Cederman, Lars-Erik. 2003b. Generating State-Size Distributions: A Geopolitical Model. Paper presented at the Agent 2003 conference on "Challenges of Social Simulation," University of Chicago, October 2-4.

Cederman, Lars-Erik. forthcoming. Computational Models of Social Forms: Advancing Process Theory. American Journal of Sociology.

Cederman, Lars-Erik, and Christopher Daase. 2003. Endogenizing Corporate Identities: The Next Step in Constructivist IR Theory. European Journal of International Relations 9 (1):5-35.

Collier, Paul, and Anke Hoeffler. 2002. Greed and Grievance in Civil Wars. World Bank (November 18).

Cusack, Thomas R., and Richard Stoll. 1990. Exploring Realpolitik: Probing International Relations Theory with Computer Simulation. Boulder: Lynnie Rienner.

Deutsch, Karl W. 1953. Nationalism and Social Communication: An Inquiry Into the Foundations of Nationality. Cambridge, Mass.: MIT Press.

Epstein, Joshua M. 2002. Modeling Civil Violence: An Agent-Based Computational Approach. Proceedings of the National Academy of Sciences 99 suppl. 3:72437250.

Fearon, James D. 2002. Why Do Some Civil Wars Last So Much Longer Than Others? Typescript, Stanford University (July 12 version).

Fearon, James D., and David D. Laitin. 2000. Violence and the Social Construction of Ethnic Identity. International Organization 54 (4):845-877.

Fearon, James D., and David D. Laitin. 2003. Ethnicity, Insurgency, and Civil War. American Political Science Review 97 (1):75-90.

Gates, Scott. 2002. Recruitment and Allegiance: The Microfoundations of Rebellion. Journal of Conflict Resolution 46 (1):111-130.

Gellner, Ernest. 1983. Nations and Nationalism. Ithaca, NY: Cornell University Press.

Gilpin, Robert. 1981. War and Change in World Politics. Cambridge: Cambridge University Press. 
Gleditsch, Nils Petter, Peter Wallensteen, Mikael Eriksson, Margareta Sollenberg, and Håvard Strand. 2002. Armed Conflict 1946-2001: A New Dataset. Journal of Peace Research 39 (5):615-537.

Gurr, Ted Robert. 1993. Minorities at Risk: A Global View of Ethnopolitical Conflicts. Washinton, DC: United States Institute of Peace Press.

Hechter, Michael. 1992. The Dynamics of Secession. Acta Sociologica 35 (4):267-283.

Herbst, Jeffrey. 1989. The Creation and Maintenance of National Boundaries in Africa. International Organization 43 (4):673-692.

Herbst, Jeffrey. 2000. States and Power in Africa: Comparative Lessons in Authority and Control. Princeton: Princeton University Press.

Hintze, Otto. 1975. The Formation of States and Constitutional Development: A Study in History and Politics. In The Historical Essays of Otto Hintze, edited by F. Gilbert. New York: Oxford University Press.

Holland, John H. 1995. Hidden Order: How Adaptation Builds Complexity. Reading, Mass.: Addison-Wesley.

Kalyvas, Stathis N. 2003. The Ontology of 'Political Violence': Action and Identity in Civil Wars. Perspectives on Politics 1 (3):475-494.

Kocher, Matthew. 2003. Human Ecology and Civil War. Dissertation in progress, Yale University.

Lake, David A. 2003. International Relations Theory and Internal Conflict: Insights from the Interstices. International Studies Review 5 (4):81-89.

Lustick, Ian S. 2000. Agent-Based Modelling of Collective Identity: Testing Constructivist Theory. Journal of Artificial Societies and Social Simulation 3 (1).

Lustick, Ian S. 2002. PS-I: A User-Friendly Agent-Based Modeling Platform for Testing Theories of Political Identity and Political Stability. Journal of Artificial Societies and Social Simulation 5 (3).

McAdam, Doug, Sidney Tarrow, and Chalres Tilly. 2001. Dynamics of Contention. Cambridge: Cambridge University Press.

Quinn, Kevin, Michael Hechter, and Erik Wibbels. 2003. Ethncity, Insurgency, and Civil War Revisited. Unpublished paper (May 6 version).

Rokkan, Stein 1999. State Formation, Nation-Building, and Mass Politics in Europe: The Theory of Stein Rokkan. Flora, Peter, ed. Oxford: Oxford University Press.

Sambanis, Nicholas. 2001. Do Ethnic and Nonethnic Civil Wars Have the Same Causes? A Theoretical and Empirical Inquiry. Journal of Conflict Resolution 45 (3):259282.

Sambanis, Nicholas. 2003. Expanding Economic Models of Civil Wars Using Case Studies. Typescript, Yale University. Forthcoming in Perspectives on Politics (November 10 version).

Sambanis, Nicholas and Annalisa Zinn. 2003. "The Escalation of Self-Determination Movements: From Protest to Violence.” Typescript, Yale University (December 4 version).

Simon, Herbert. 1981. The Sciences of the Artificial. Cambridge, MA: The MIT Press.

Skaperdas, Stergios. 2003. An Economic Approach to Analyzing Civil Wars. Paper presented at the World Bank's workshop on "Civil Wars and Post-Conflict Transitions," held at UC Irvine.

Sollenberg, Margareta, and Peter Wallensteen. 2001. Patterns of Major Armed Conflicts, 1990-2000. In SIPRI Yearbook 2001. Armaments, Disarmament and International Security. Oxford: Oxford University Press.

Tilly, Chalres. 2003. The Political of Collective Violence. Cambridge: Cambridge University Press.

Toft, Monica Duffy. 2003. The Geography of Ethnic Violence: Identity, Interests, and the Indivisibility of Territory. Princeton: Princeton University Press.

Weber, Eugen. 1976. Peasants into Frenchmen: The Modernization of Rural France, 1870-1914. Stanford: Stanford University Press. 
Weiner, Myron. 1971. The Macedonian Syndrome: An Historical Model of International Relations and Political Development. World Politics 23 (4):665-683.

Weiner, Myron. 1978. Sons of the Soil: Migration and Ethnic Conflict in India. Princeton: Princeton University Press. 


\section{Tables}

Table 1. Logit regression of simulated data for different levels of nationalist solidarity

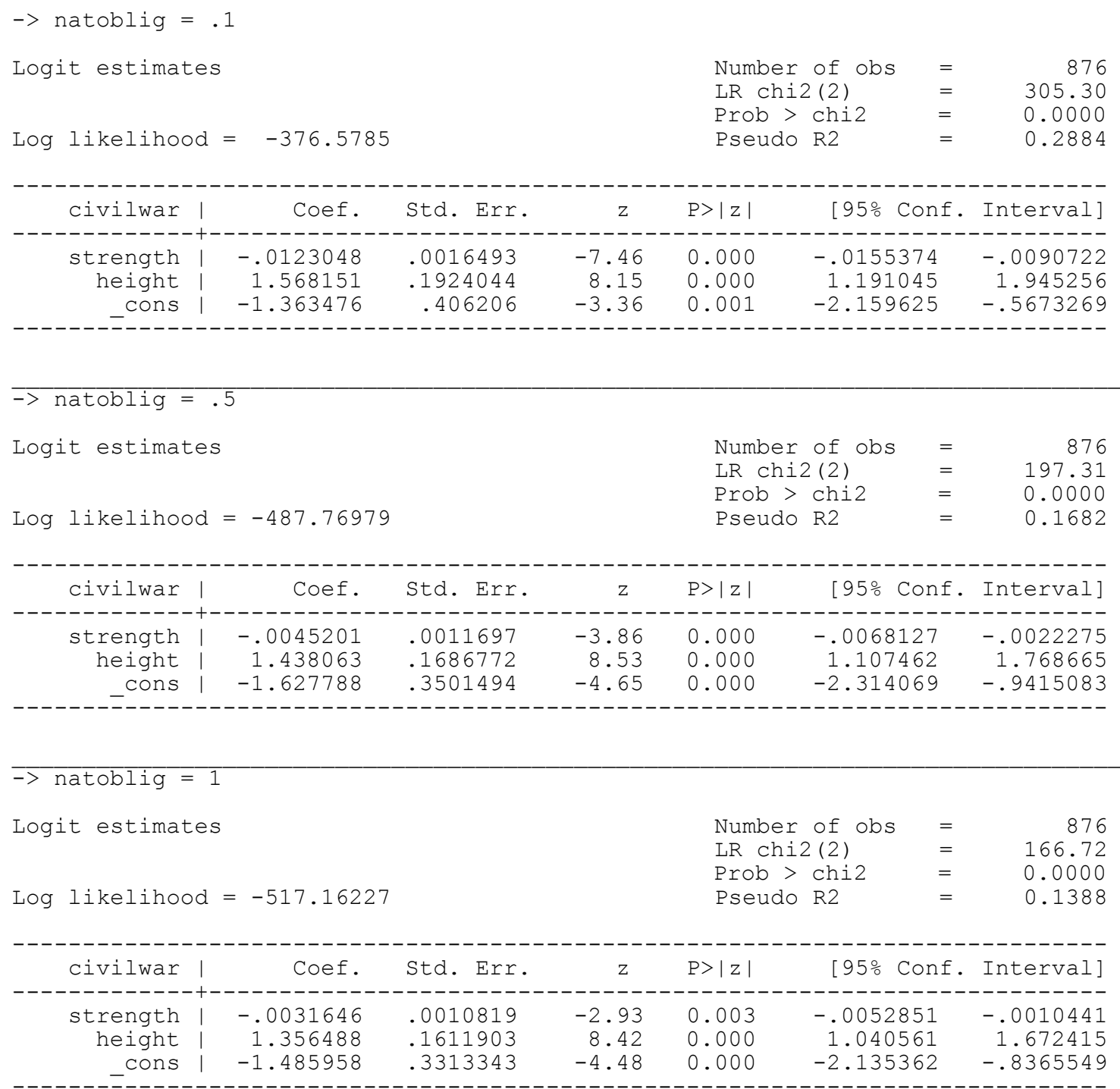


Table 2. Logit regression of simulated data for different levels of nationalist solidarity

$->$ natoblig $=.1$

Logit estimates

Number of obs=

$\mathrm{LR} \operatorname{chi2}(4)=627.77$

Prob $>$ chi2 $=0.0000$

Log likelihood $=-215.34309$

Pseudo R2 $2 \quad 0.5931$

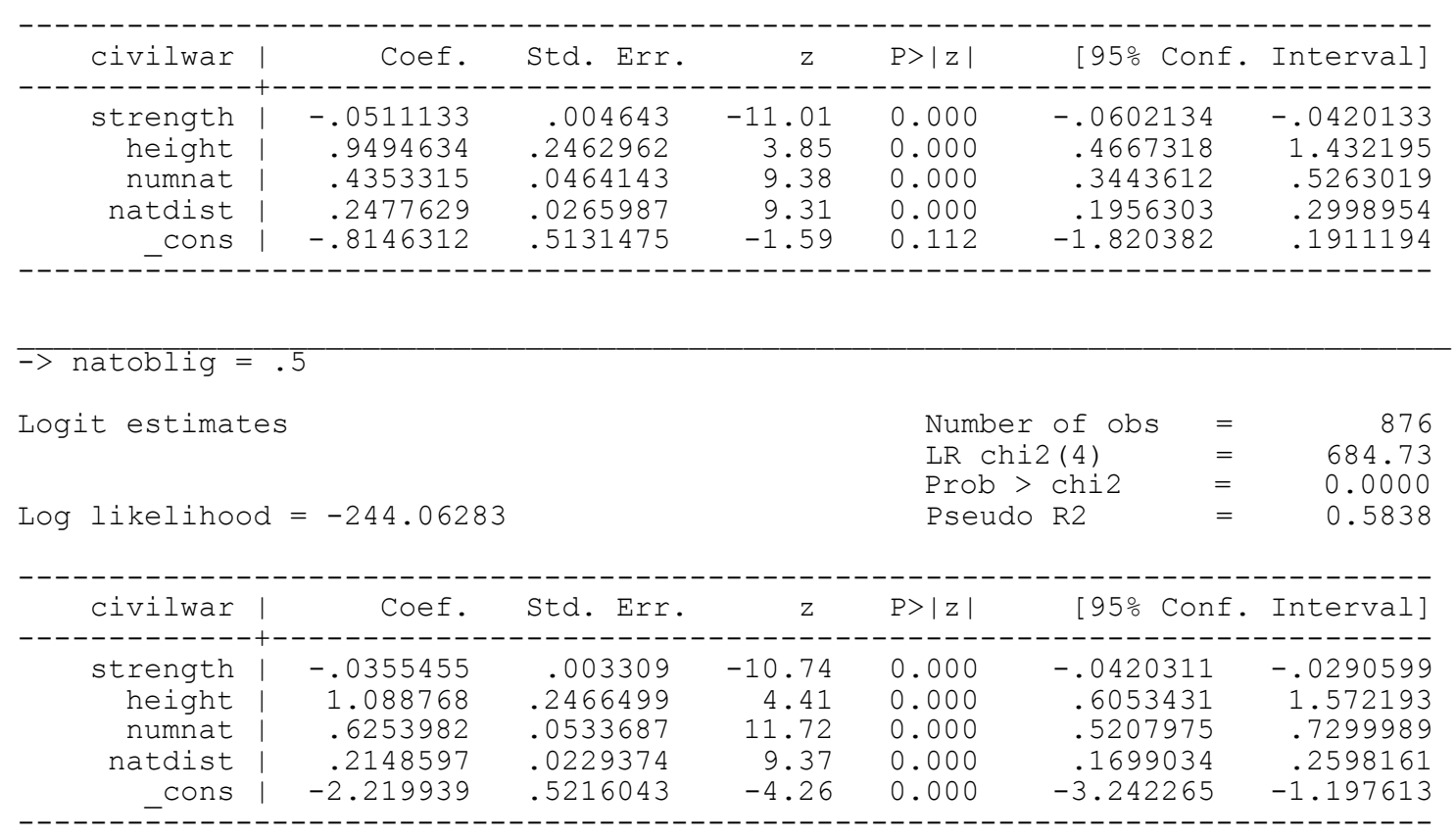

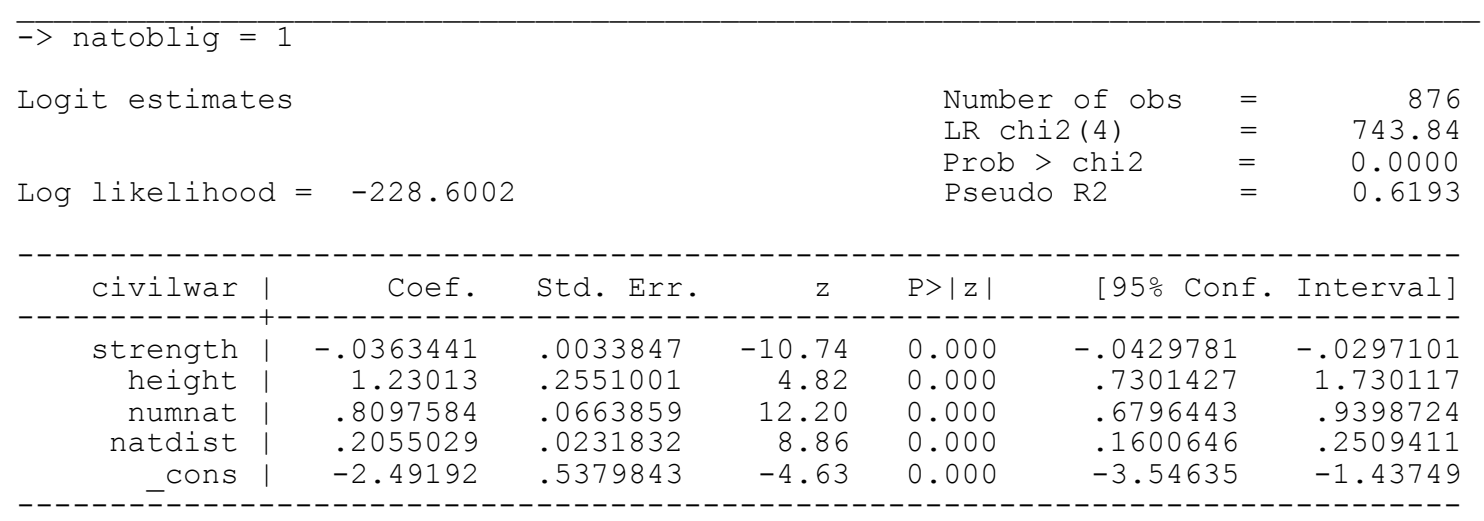




\section{Table 3. Logit regression of simulated data for different levels of rugged terrain}

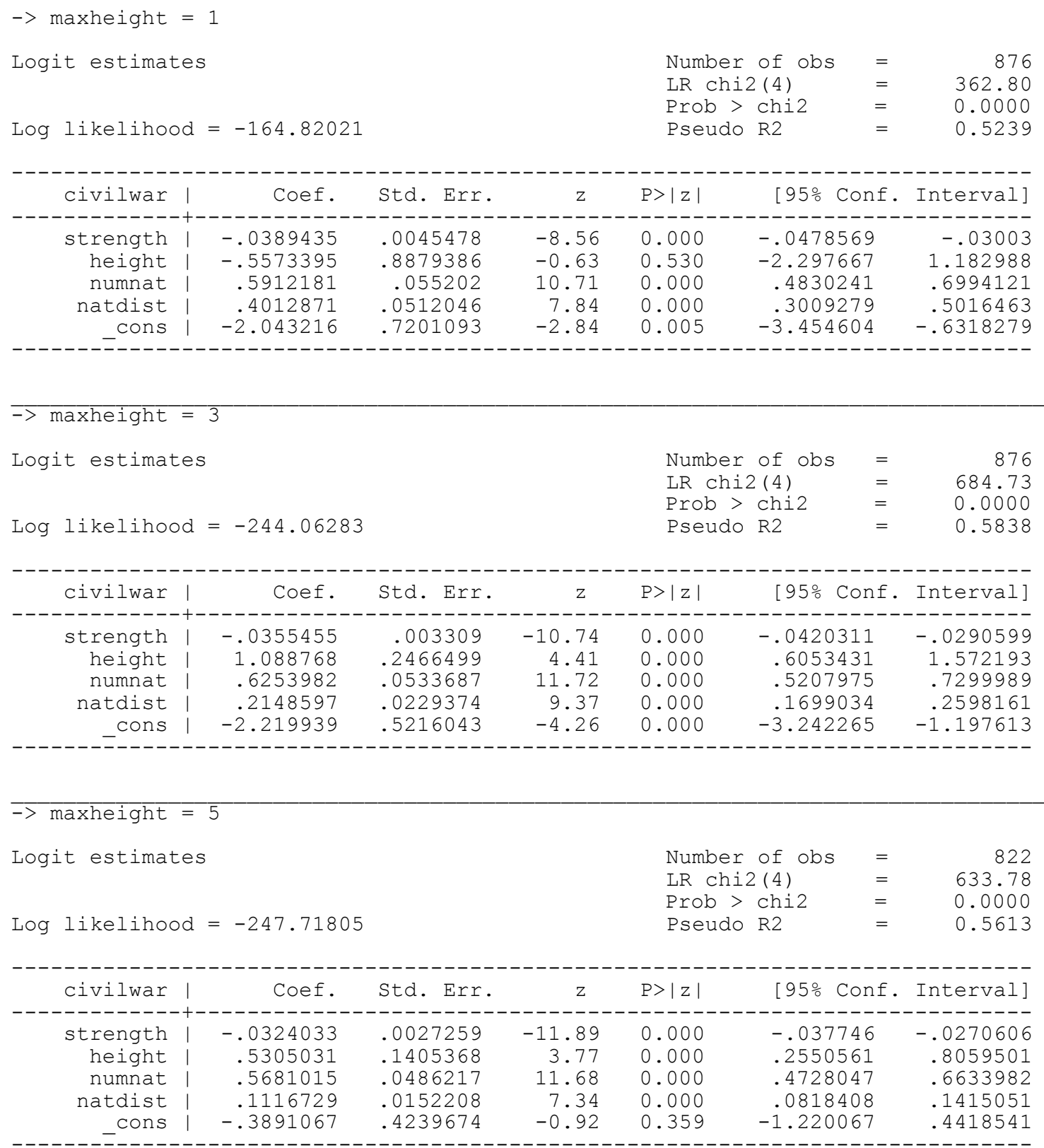




\section{Table 4. Logit regression of simulated data for different numbers of ethnies}

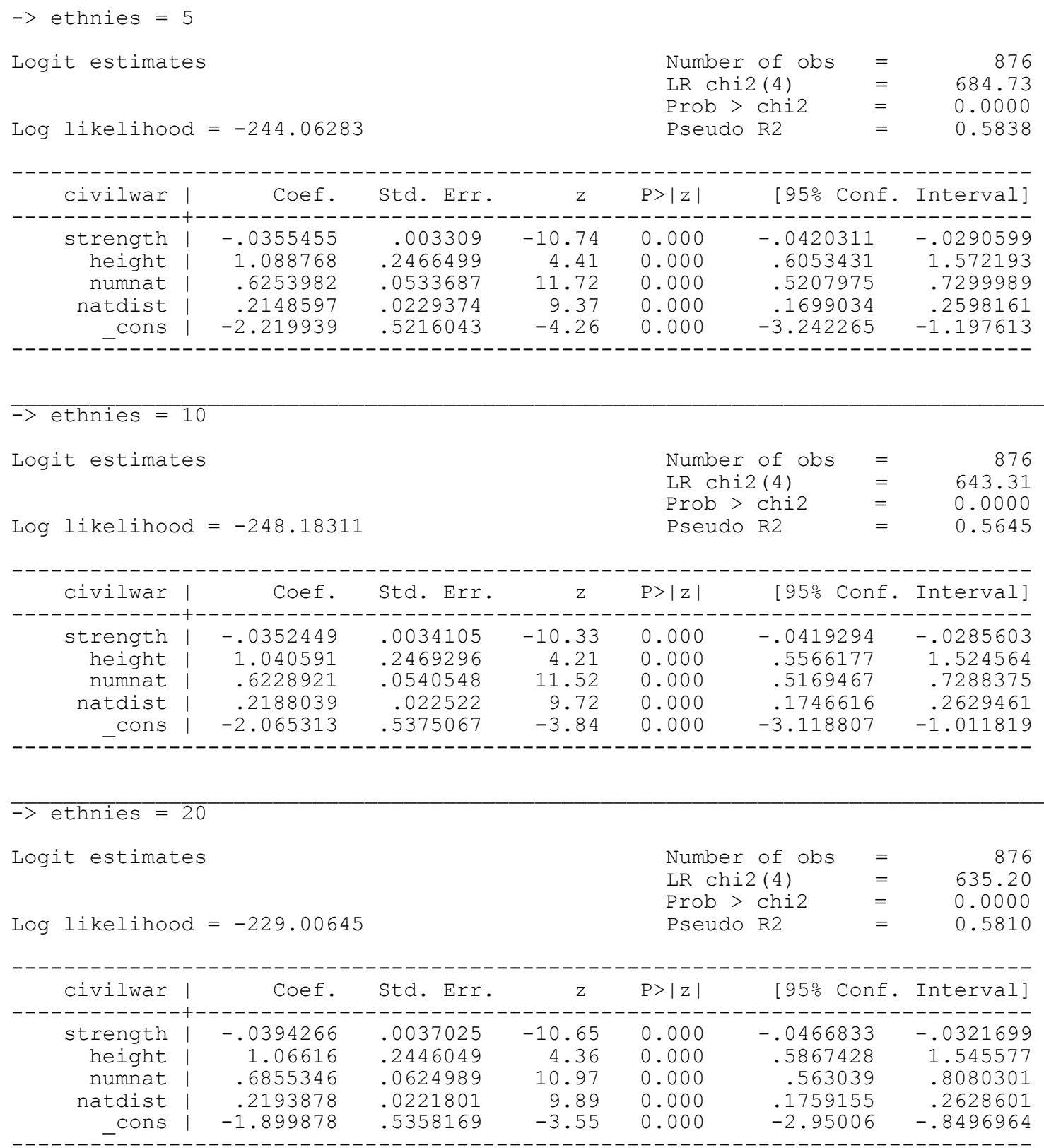




\section{Table 5. Logit regression of simulated data for different levels of cultural drift}

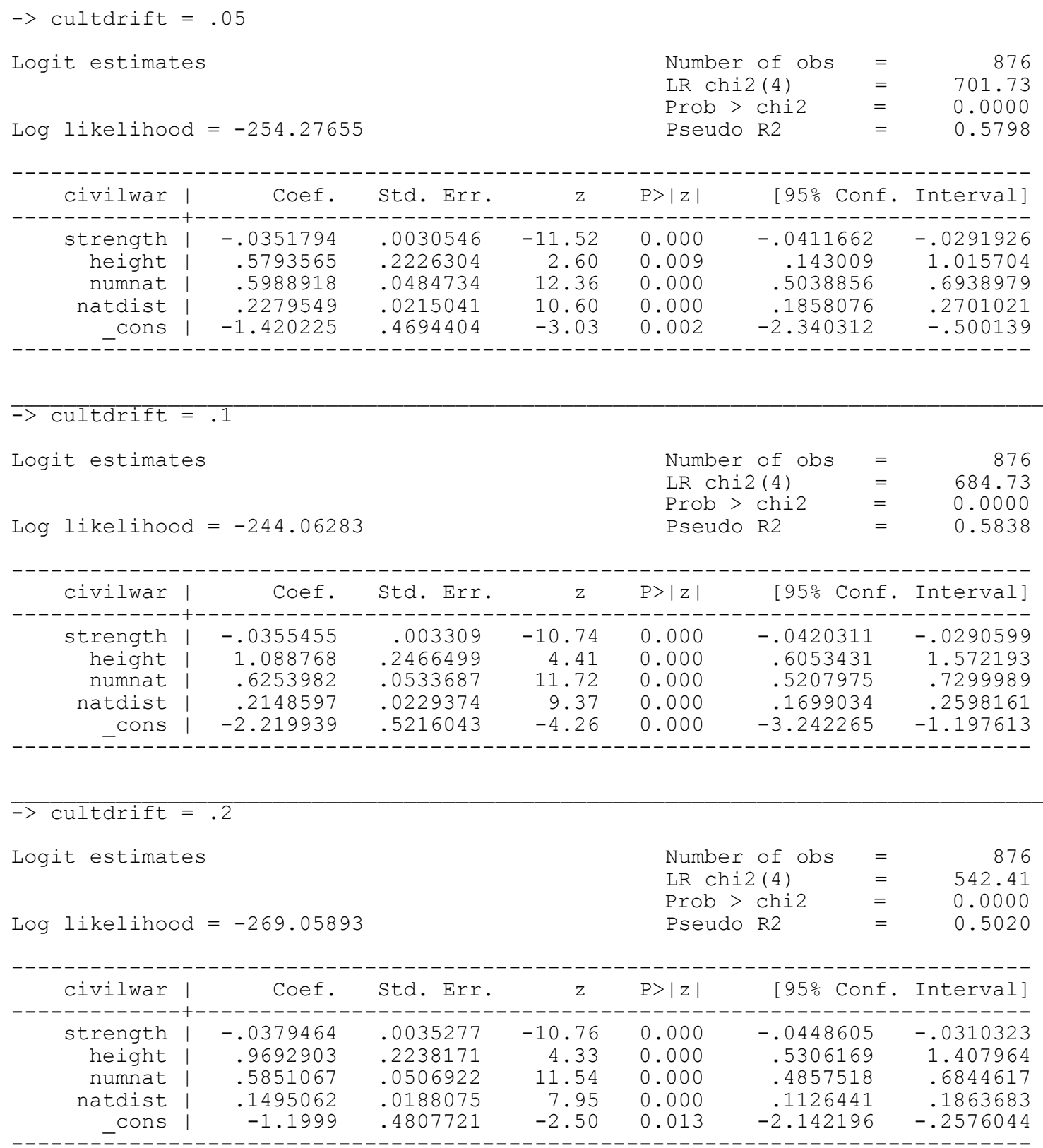




\section{Table 6. Logit regression of simulated data for different levels of assimilation}

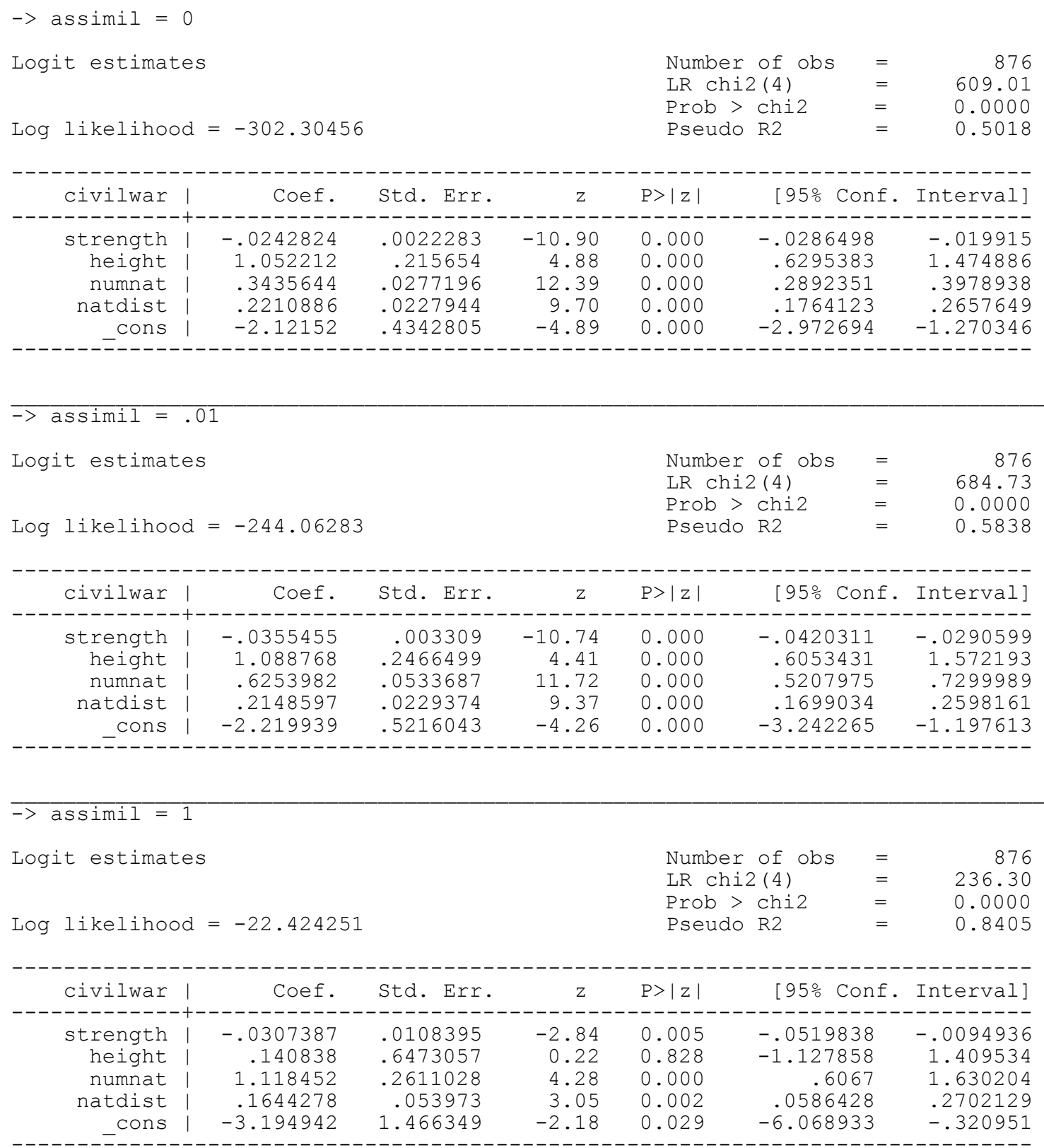




\section{Table 7. Logit regression of simulated data for different levels of identity exclusiveness}

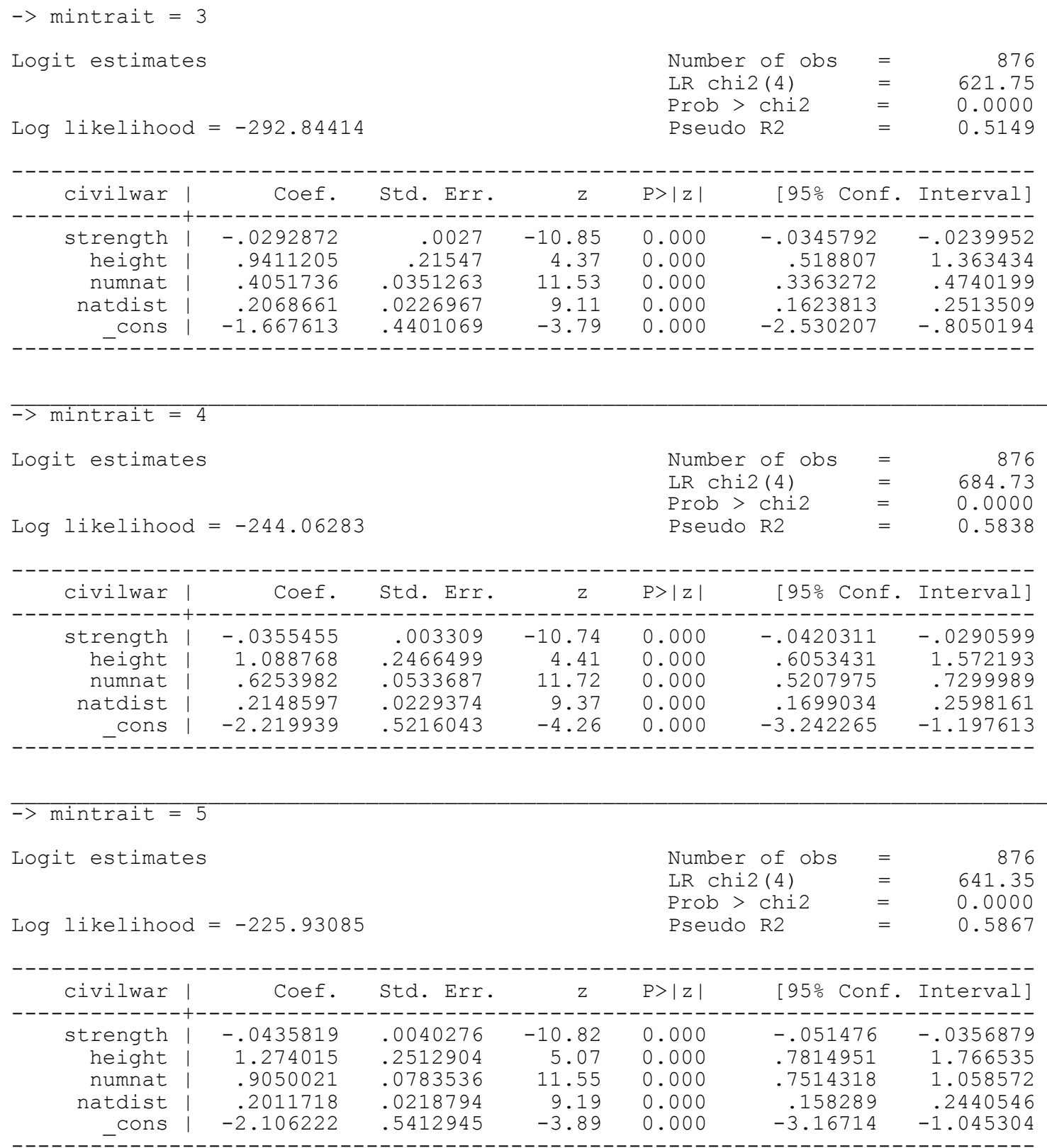


Figures

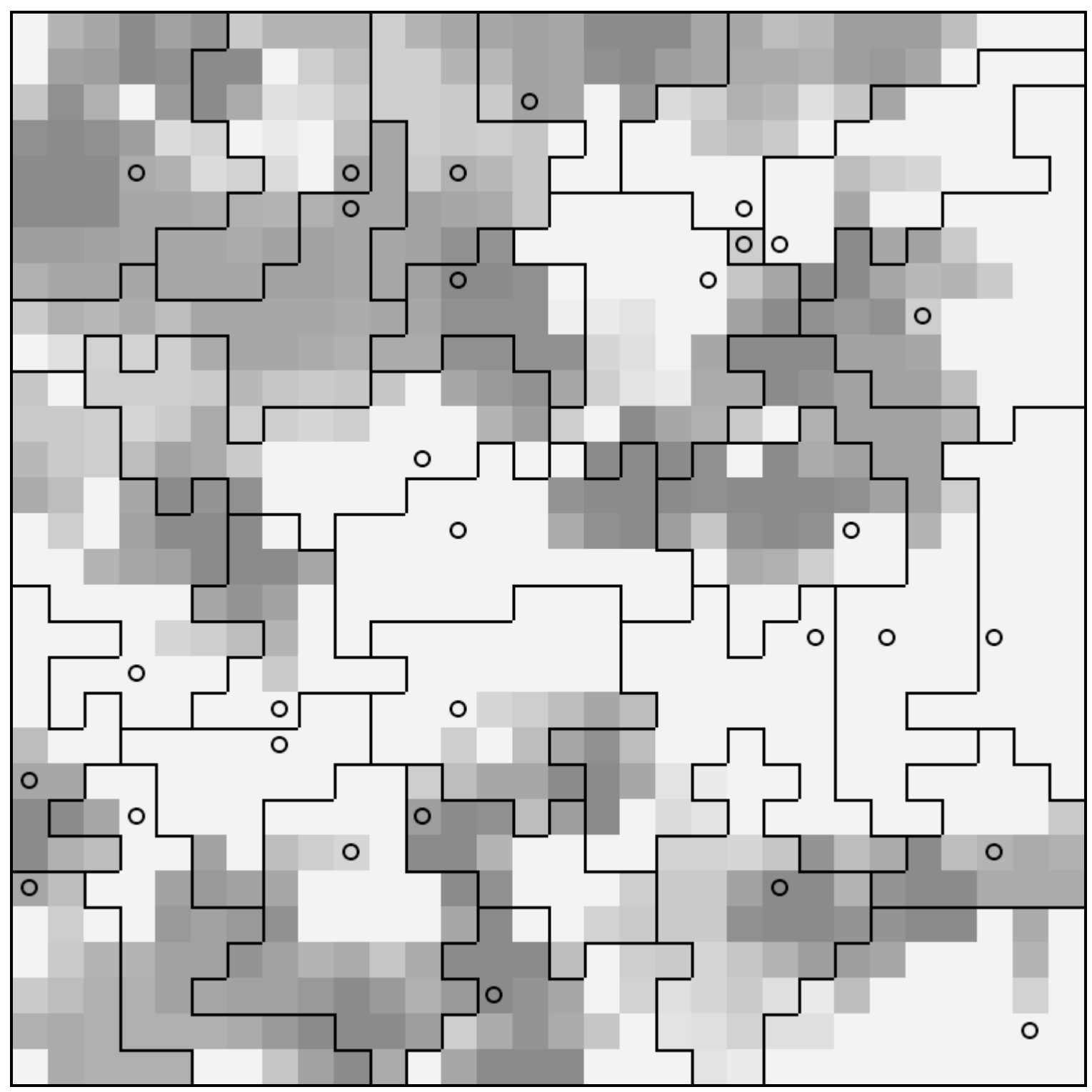

Figure 1. Varied terrain inhabited by 30 states at time at the end of Phase I. 


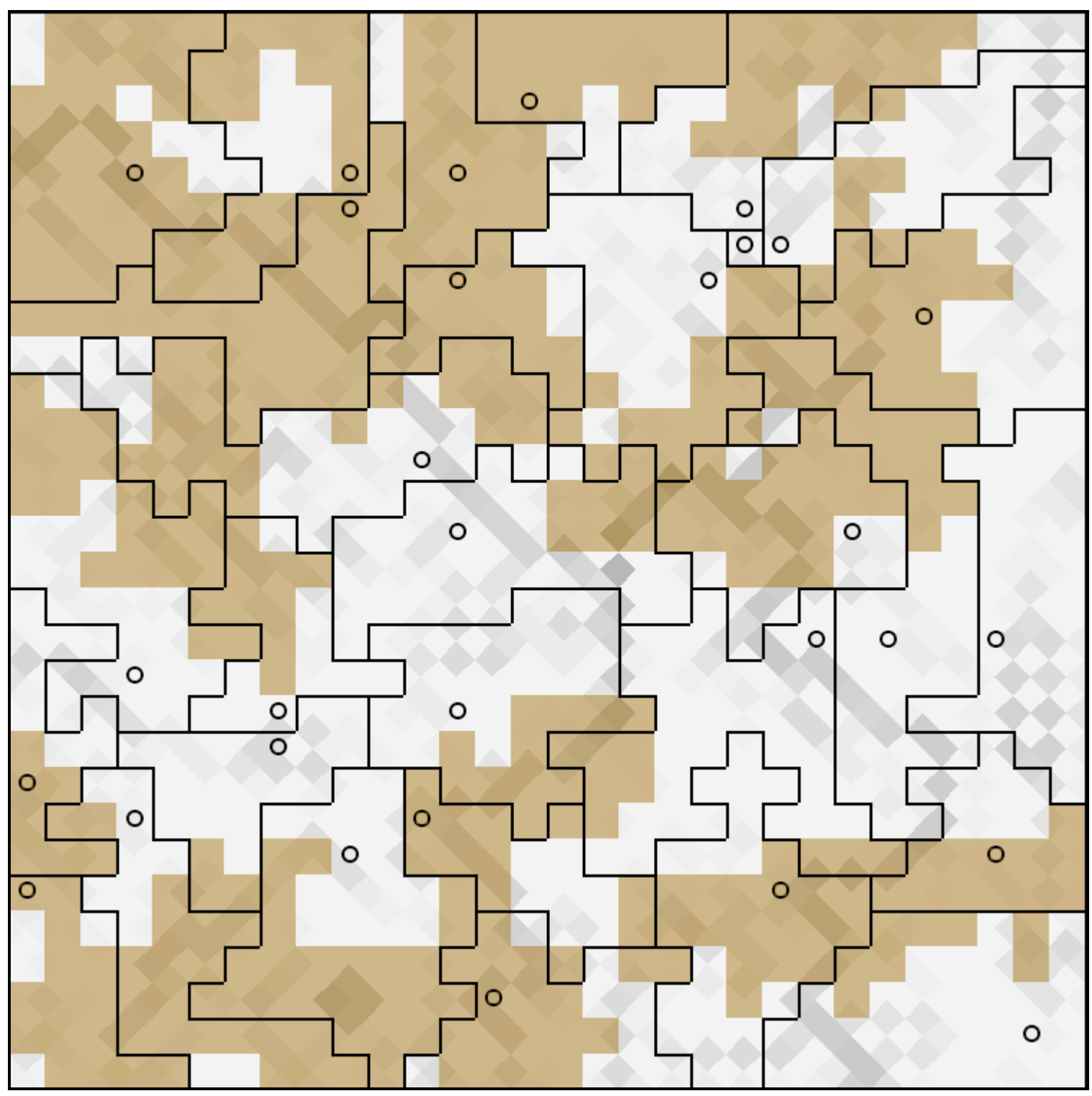

Figure 2. A cultural map shown together with mountain contours at the end of Phase I. 


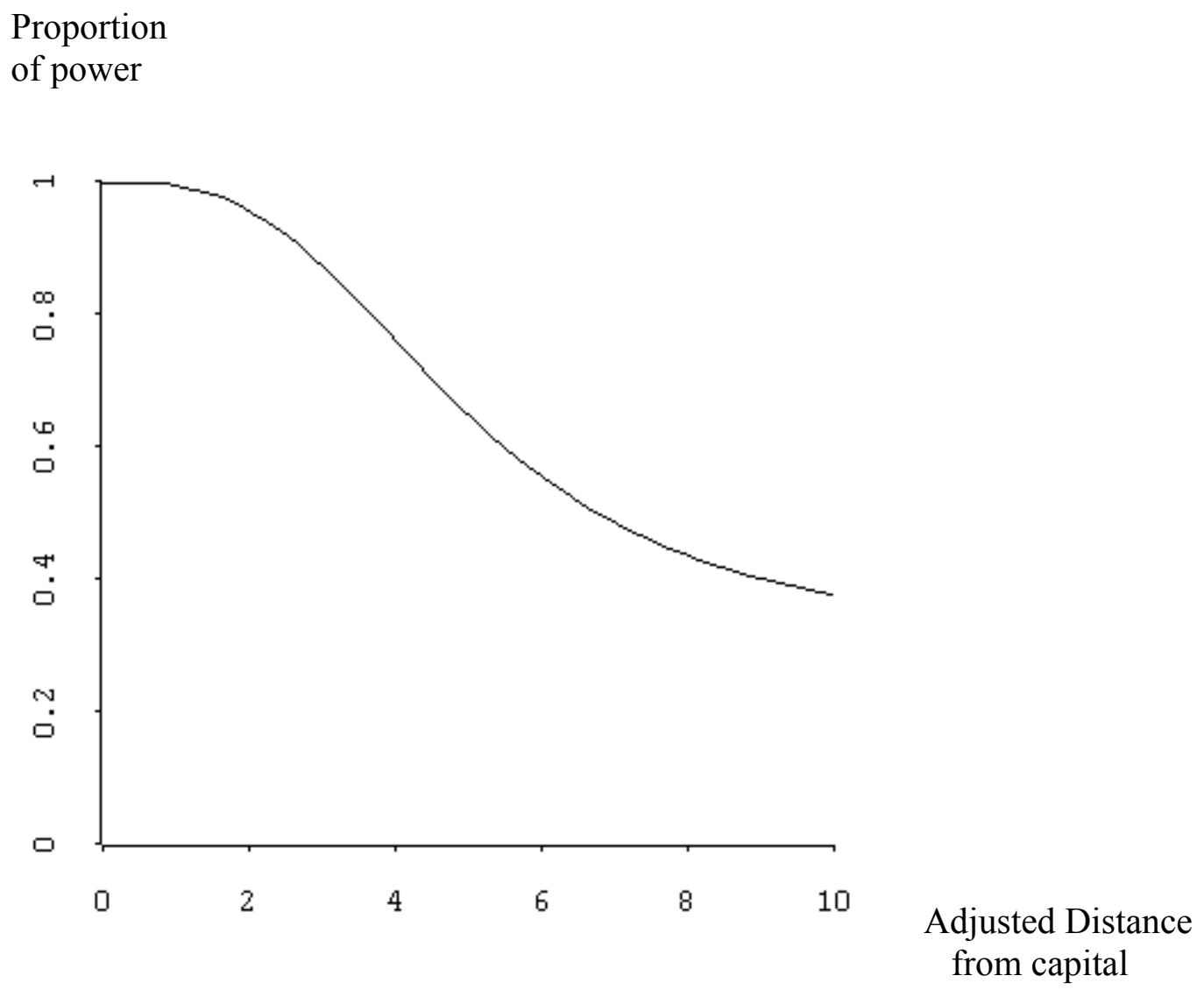

Figure 3. Terrain-adjusted loss-of-strength gradient affecting power extraction and projection. 


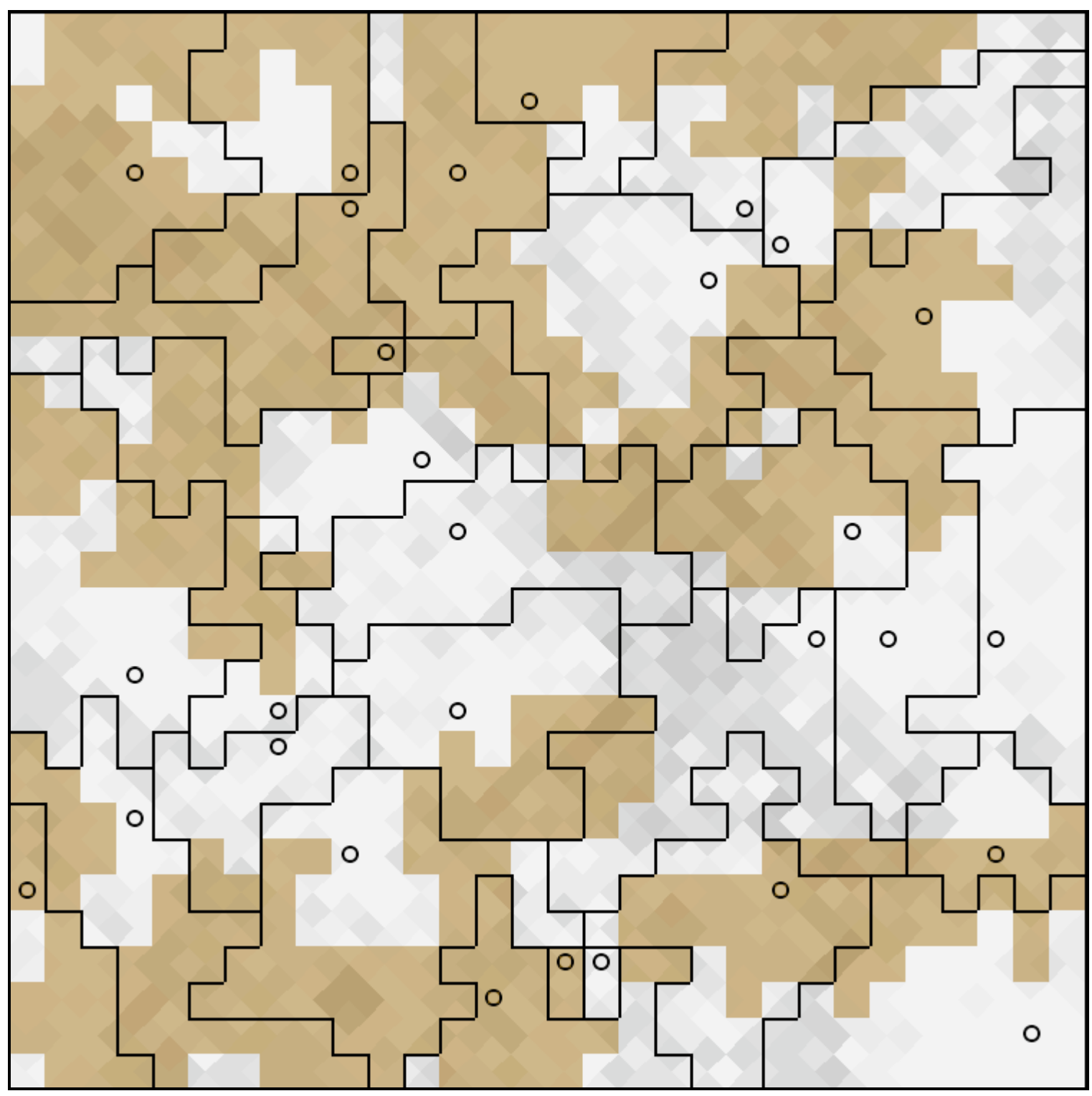

Figure 4. The system at the end of Phase II, after some consolidation and assimilation. 


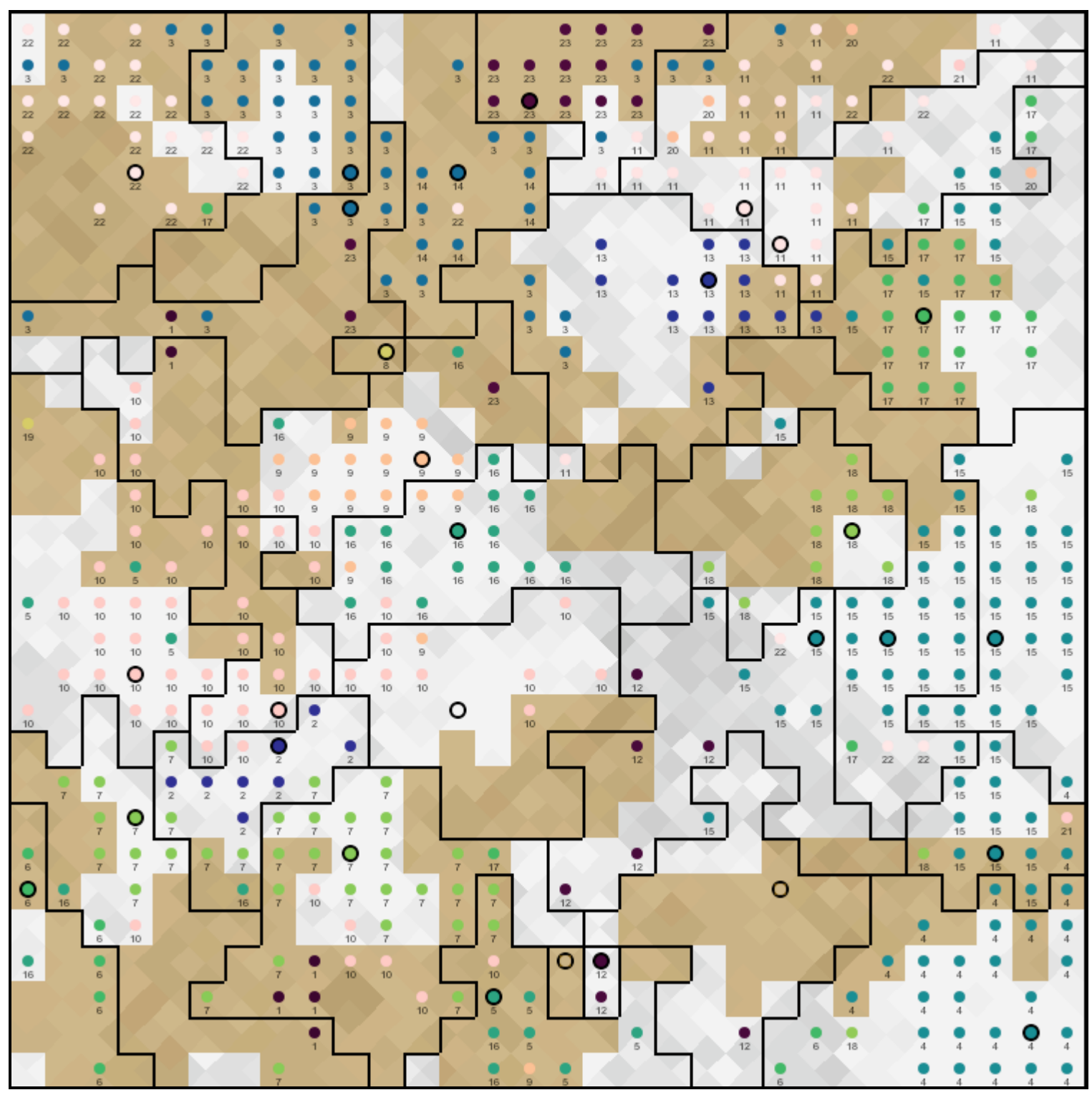

Figure 5. Mobilized populations after the end of Phase III. 


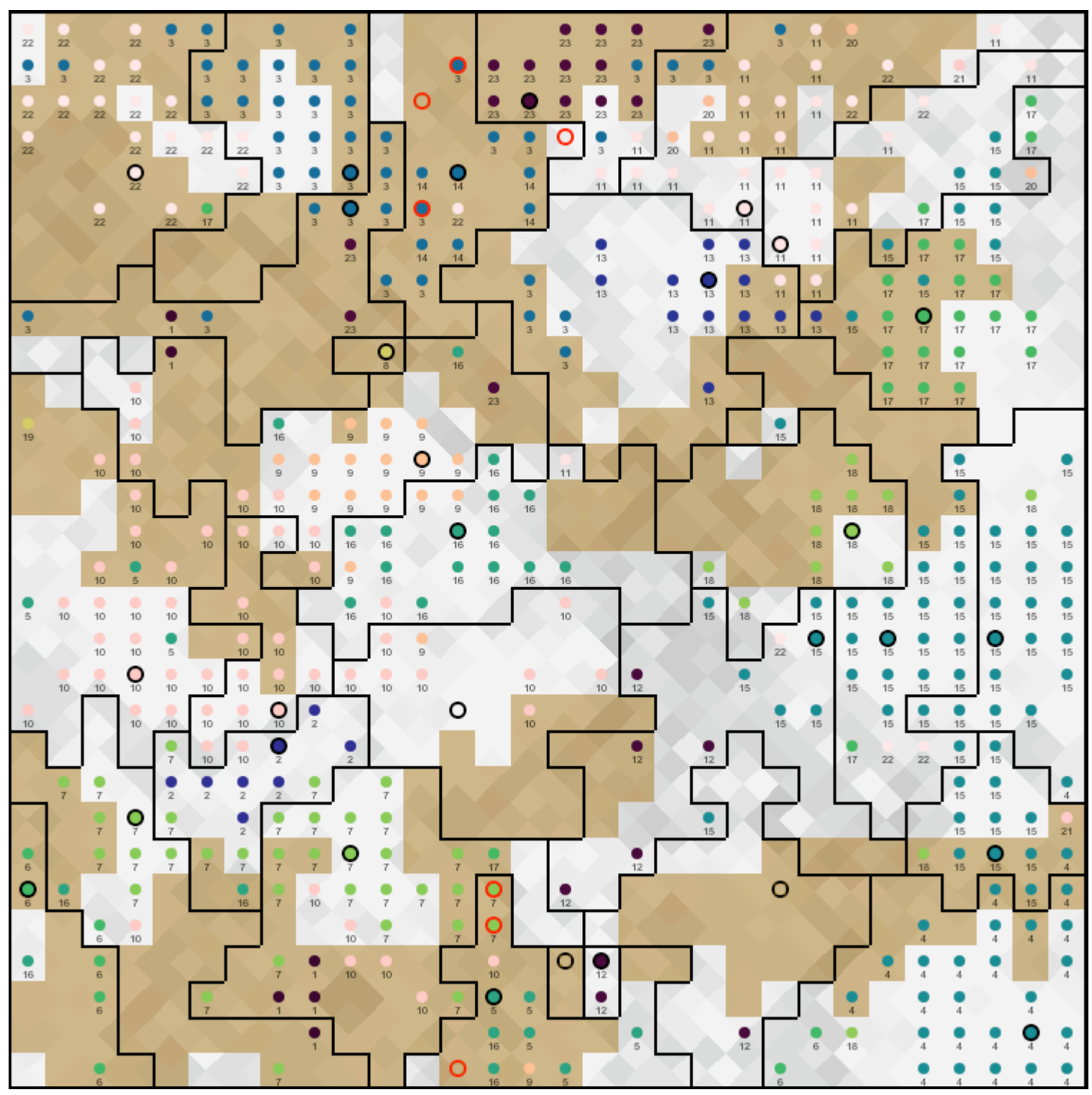

Figure 6. Civil wars raging in two multinational states during Phase IV (see red rings). 